\title{
VALIDATION OF A CFD MODEL PREDICTING THE EFFECT OF HIGH LEVEL LATERAL ACCELERATION SLOSHING ON THE HEAT TRANSFER AND PRESSURE DROP IN A SMALL-SCALE TANK IN NORMAL GRAVITY
}

\author{
O. Kartuzova and M. Kassemi \\ National Center for Space Exploration Research \\ at NASA Glenn Research Center \\ Cleveland, $\mathrm{OH}$, USA
}

\begin{abstract}
A two-phase CFD model is developed to study the effects of sloshing with high level lateral acceleration on the heat transfer and pressure drop in a small scale tank. Computational results are compared to the data provided by a non-isothermal sloshing experiment without phase change conducted by $\mathrm{T}$. Himeno et al. at the University of Tokyo and JAXA in 2011 [1]. The results of the current model are, also, compared to CFD predictions reported by Himeno et al. [2]. A step change in lateral acceleration was applied in the experiment. Different levels of lateral acceleration amplitude, varying between $0 \mathrm{G}$ and $0.5 \mathrm{G}$, were considered. CFD results for interface movement and tank pressure are presented and compared in this paper to the experimental data for the case in which the value of lateral acceleration was set to $0.5 \mathrm{G}$. The effects of initial and boundary conditions and turbulence modeling approach on the tank pressure change during sloshing are discussed in detail. The effect of conjugate heat transfer in the tank wall is also studied to show its important role in determining the tank pressure evolution. The results of the Reynolds Averaged Navier Stokes (RANS) models are compared to the results of the Large Eddy Simulation model (LES) to underscore the importance of correctly capturing the effects of turbulence for high fidelity predictions.
\end{abstract}

\section{INTRODUCTION}

Sloshing is a phenomenon that occurs in a partially filled two-phase tank, when the tank is subjected to a sudden movement or acceleration. The acceleration disturbs the liquidvapor interface leading to deformation and oscillations around its initial mean position. If the disturbance is strong enough, sloshing can endanger the structural integrity of the tank both through direct fluid structural loading of the tank wall or by affecting the internal tank pressure. Eventually, liquid inertia and viscosity dampens the magnitude of the oscillations and the impact of sloshing with time.

The indirect impact of sloshing, which is the subject of the present study, occurs when the oscillating liquid cools large portions of the hotter tank surfaces originally exposed to the warmer gas. As a result, the hot gas eventually contacts a cooler tank surface resulting in both temperature and pressure decline in the gaseous region. Increase in the liquid-gas interface area due to interface deformation and splashing together with turbulent mixing effects also results in an augmentation of heat transfer from vapor to liquid causing a further reduction of tank pressure. In volatile fluids, the interfacial heat transfer is accompanied by phase change mass transfer resulting in additional pressure reduction. In cryogenic storage tanks such pressure collapses due to vigorous sloshing may result in engine pump cavitation, thrust degeneration during engine operation. Moreover, significant pressure reduction in a cryogenic tank is a major concern for its structural stability if the pressure falls beyond buckling limit of the tank.

Due to high costs of conducting experiments with cryogenic fluids at different levels of gravitational acceleration, it has become advantageous to conduct experiments with simulant fluids, as well as, develop Computational Fluid Dynamics (CFD) models to capture the physical phenomena. These models then have to be validated against the experiments to ensure that they can reliably predict the propellant behavior during launch and in space.

The sloshing phenomenon is accompanied by vigorous interface motion and deformation. Several different interfacecapturing methods have been used to track the interface in the computational work to date, The MAC method was used by Iglesias et al. [3], as well as, Nam and Kim [4] for simulating violent sloshing flows in two-dimensional tanks. Lee et al. [5] employed the VOF method, as incorporated in the CFD code 
FLOW3D for the free surface prediction of an LNG tank sloshing load. Wemmenhove et al. [6, 7] extended the VOF method to develop a compressible two phase flow model for more accurate simulation of LNG tank sloshing. A level-set Reynolds Averaged Navier-Stokes (RANS) methodology was developed and used by Chen [8, 9, 10] for time-domain simulation of sloshing in a three-dimensional membrane-type LNG tank.

The dynamics of the sloshing phenomenon has been extensively studied at NASA since the 1960's [11]. Recently, thermal de-stratification and pressure reduction from lateral sloshing has been investigated experimentally and numerically by Himeno et al. [1, 2], Lacapere et al. [12], Agui and Moder [13]. While focusing on predicting the thermal de-stratification and pressure drop in the tank, these computational studies did not include an extensive analysis of the factors that can affect the modeling of the sloshing process. These factors can include, but limited to: the effect of the conjugate heat transfer in the tank wall and the impact of different turbulence modeling approaches.

This paper presents a two-phase CFD model developed to study sloshing generated by a high level lateral acceleration and its effects on the ensuing heat transfer and pressure drop in a small scale tank. In this model the interface is captured using the Volume of Fluid (VOF) method [14]. The conjugate heat transfer in the tank wall is included in the model. Results are analyzed, and validated against $1 \mathrm{G}$ experimental measurements. The effects of initial and boundary conditions and turbulence modeling approach on the tank pressure change during sloshing are discussed in detail.

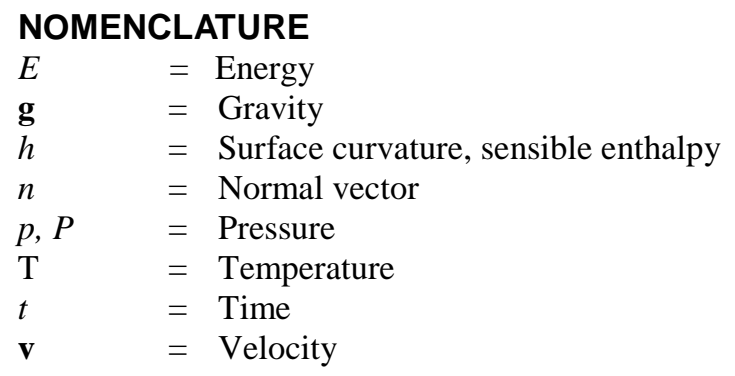

\section{Greek}

$\alpha=$ Cell value of volume fraction

$\mu \quad=$ Dynamic viscosity

$\rho=$ Density

\section{$\underline{\text { Subscripts }}$}

$q \quad=$ Interface or phase

\section{EXPERIEMTNAL SETUP}

The test tank used in the experiment for silicone oil sloshing has a cylindrical shape with $0.110 \mathrm{~m}$ inner diameter and $0.230 \mathrm{~m}$ height [1]. The tank, made of acrylic resin, is mounted on a slider to allow lateral movement. The tank is filled with cold silicone oil to $0.110 \mathrm{~m}$ level measured from the bottom of the tank. The test tank and experimental setup [1] are shown in Figure 1.
A step change in lateral acceleration was applied in the experiment. Different levels of lateral acceleration amplitude, varying between $0 \mathrm{G}$ and $0.5 \mathrm{G}$, were considered.

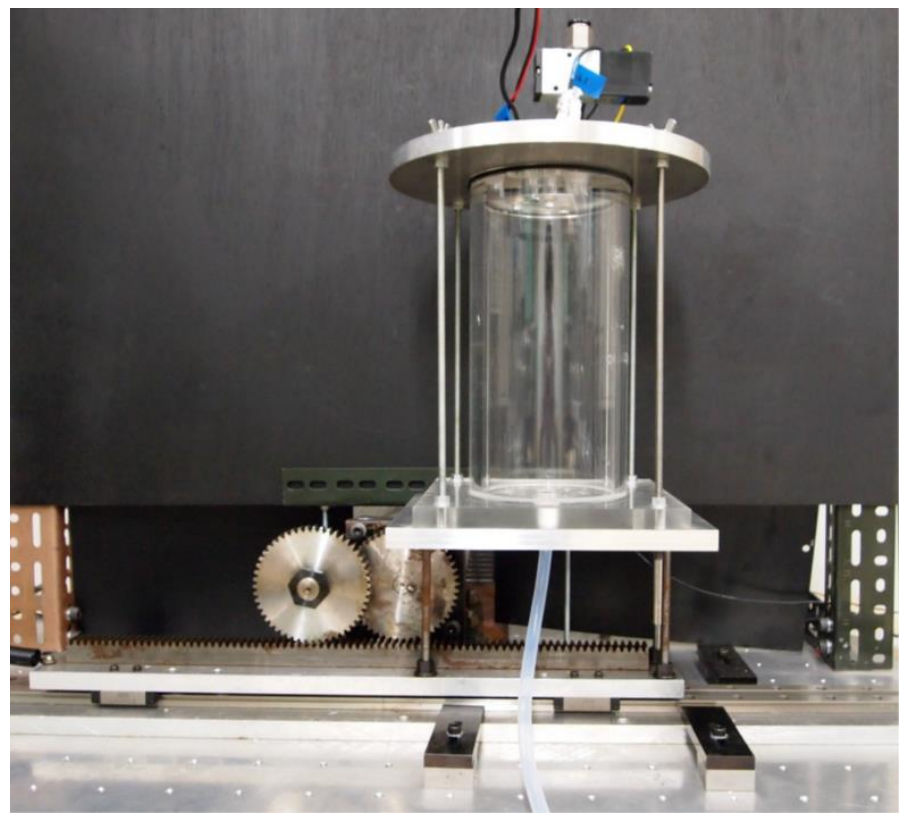

Figure 1. The test tank for silicone oil sloshing experiment [1]

\section{MATHEMATICAL MODEL}

\section{Governing Equations}

The fluid flow and heat transfer in the tank are described in terms of the continuity, Navier-Stokes, and energy equations for both phases:

$$
\begin{aligned}
& \frac{\partial \rho}{\partial t}+\nabla(\rho \mathbf{v})=0, \\
& \frac{\partial}{\partial t}(\rho \mathbf{v})+\nabla(\rho \mathbf{v} \mathbf{v})=-\nabla p+\nabla\left[\mu_{e f f}\left(\nabla \mathbf{v}+\nabla \mathbf{v}^{T}\right)\right]+
\end{aligned}
$$

$$
+\rho \mathbf{g}+\mathbf{F}_{v o l}
$$

$\frac{\partial}{\partial t}(\rho E)+\nabla(\mathbf{v}(\rho E+p))=\nabla\left(k_{e f f} \nabla T\right)+S_{h}$

In solid regions (when conjugate heat transfer is considered) the energy transport equation has the following form:

$\frac{\partial}{\partial t}(\rho h)+\nabla(\mathbf{v} \rho h)=\nabla(k \nabla T)+S_{h}$ 
where $\mathbf{F}_{v o l}$ is a model dependent volumetric source term; $S_{h}$ is a volumetric heat source term.

Conjugate simulations are referred to coupled fluidsolid temperature calculations. In the present study, the liquid phase is treated as incompressible. The gas is modeled as a compressible ideal gas. The primary focus of this study is to capture the main dynamics of the fluid flow and phase distribution and their effect on heat transfer inside the tank during sloshing. The movement of the interface is captured diffusely using the Volume-Of-Fluid (VOF) method, as promulgated by Hirt and Nichols [14]; this method is described below.

\section{VOF Model}

In the VOF method, a volume fraction is defined in each cell such that the volume fractions of all of the phases sum to unity. In each cell, the change in the interface can be tracked by solving a continuity equation for the volume fraction of the $q^{\text {th }}$ phase:

$\frac{1}{\rho_{q}}\left[\frac{\partial}{\partial t}\left(\alpha_{q} \rho_{q}\right)+\nabla \cdot\left(\alpha_{q} \rho_{q} \mathbf{v}_{q}\right)=S_{\alpha_{q}}\right]$

where the volume fraction for the primary phase is determined from:

$$
\sum_{q=1}^{n} \alpha_{q}=1
$$

In the VOF method, the field variables and properties are defined in terms of the volume fraction, which for a general system can be written as:

$$
\begin{array}{r}
\rho=\sum_{q=1}^{n} \alpha_{q} \rho_{q}, \quad \mu_{e f f}=\sum_{q=1}^{n} \alpha_{q} \mu_{e f f_{q^{\prime}}} \\
k_{\text {eff }}=\sum_{q=1}^{n} \alpha_{q} k_{\text {eff }} .
\end{array}
$$

In this fashion, the continuity, momentum, and energy equations, as described by Eq. (1) - (3), can be solved throughout the domain for the temperatures and velocities in the two phases. In the VOF model, the energy $(E)$ and temperature $(T)$ are treated as mass-averaged variables:

$$
E=\frac{\sum_{q=1}^{n} \alpha_{q} \rho_{q} E_{q}}{\sum_{q=1}^{n} \alpha_{q} \rho_{q}}
$$

where $E_{q}$ is based on the specific heat of the $q^{\text {th }}$ phase and the shared temperature.

In the present implementation, the surface tension forces at the interface are modeled via the Continuum Surface Force (CSF) model of Brackbill et al. [15]. In this model, the surface tension forces at the interface are transformed into a volume force $\left(\mathbf{F}_{v o l}\right)$, which is added as a source to the momentum equation:

$$
\mathbf{F}_{\text {vol }}=\sum_{\text {pairs } i j, i<j} \sigma_{i j} \frac{\alpha_{i} \rho_{i} h_{i} \nabla \alpha_{j}+\alpha_{j} \rho_{j} h_{j} \nabla \alpha_{i}}{\frac{1}{2}\left(\rho_{i}+\rho_{j}\right)}
$$

where $h_{i}$ is the surface curvature calculated from the local gradients in the surface normal at the interface:

$h_{i}=\nabla \cdot \widehat{\mathbf{n}}$.

\section{Turbulence modeling}

Reynolds Averaged Navier-Stokes (RANS) approach to turbulence modeling is compared in this paper with the Large Eddie Simulation (LES) method for simulating sloshing in a tank. The Shear Stress Transport $k-\omega$ RANS model of Menter [16] was utilized. This model is similar to the standard $k-\omega$ model of Wilcox [17], but has the ability to account for the transport of the principal shear stress in adverse pressure gradient boundary layers. The model is based on the assumption of Bradshaw et al. [18] that the principal shear stress is proportional to the turbulent kinetic energy, which is introduced into the definition of the eddy-viscosity. These features make the $k-\omega$ SST model more accurate and reliable for a wider class of flows than the standard $k-\omega$ model. In the VOF model, continuity of the turbulent quantities is inherently assumed since one set of equations for the turbulent kinetic energy and dissipation rate is solved for both phases throughout the domain, with the fluid properties varying according to the local volume fraction value.

In the $L E S$ model large eddies are resolved directly, while small eddies are modeled. In the current LES model the Wall-Adapting Local Eddy-Viscosity (WALE) [19] sub-grid scale model is utilized for modeling unknown stresses resulting from the filtering operation.

\section{NUMERICAL IMPLEMENTATION}

\section{Initial Conditions}

Fluid temperatures 30 seconds prior to the beginning of sloshing, measured in the experiment, are shown in Fig. 2. Only one measured temperature profile was provided, so it was used for all cases simulated, however, the actual fluid temperature might be different for different cases, based on the sequence of events prior to the beginning of each test. To obtain initial conditions for sloshing cases a simulation, using temperature profile, shown in Fig. 2, was performed without sloshing for 30 seconds. In this simulation the interface was treated as a sharp rigid boundary line hence forth referred to as the Sharp Interface Model. Temperature and velocity at the end of this simulation were used as initial conditions for the sloshing case. Since the tank wall temperatures were seemingly not measured in the experiment, different values were applied and the results are presented in the results and discussion section of this paper. 
Initial values for turbulence kinetic energy and specific dissipation rate were set, respectively, to $1 \mathrm{e}-06, \mathrm{~m}^{2} / \mathrm{s}^{2}$ and $100,1 / \mathrm{s}$.

\section{Boundary Conditions}

In the experiment, the tank, made of acrylic with wall thickness equal to $10 \mathrm{~mm}$, was exposed to ambient air on the sides. The top and bottom were attached to a slider mechanism made of metal. In this work, simulations with and without tank wall were performed. In the cases without tank wall, adiabatic boundary conditions were applied on the fluid-wall boundary. In the cases with the tank wall, convection and radiation between the outer boundary of the tank wall and surrounding air at $298 \mathrm{~K}$ were considered. At the tank bottom, constant temperature boundary condition was used, since the metal plate in contact with cold silicone oil was assumed to be at the temperature of the silicone oil (282.5 K). No slip boundary conditions were applied on the tank wall surface in contact with fluid.

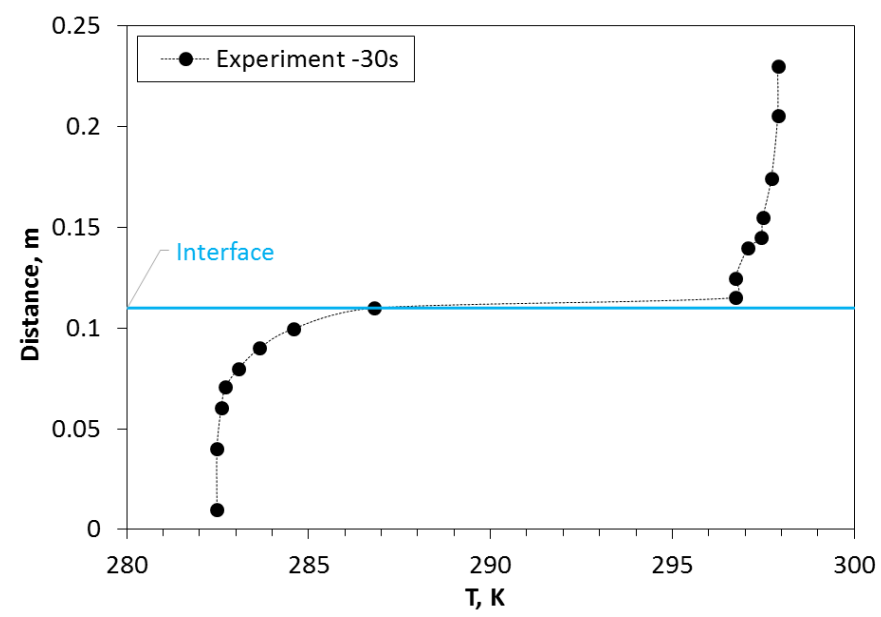

Figure 2: Measured initial fluid temperature (30 seconds before sloshing)

\section{Material Properties:}

Fluid

Constant material properties were used for the working fluids: silicone oil KF96L-1cSt and air. The properties are summarized in Table 1. The silicone oil properties were obtained from:

https://www.shinetsusiliconeglobal.com/catalog/pdf/kf96_e.pdf

Air properties were taken from ANSYS Fluent database [20].

Tank Wall (Acrylic)

Constant properties for tank wall material acrylic were used. The properties are summarized in Table 2 .

\section{Computational mesh}

Three different computational grids were used in the current study. Two of them include the tank wall and one does not.
Table 1. Silicone oil KF96L-1cSt properties

\begin{tabular}{|l|c|c|c|}
\hline Property & Units & Silicone Oil & Air \\
\hline Density & $\mathrm{kg} / \mathrm{m}^{3}$ & 818 & Ideal gas \\
\hline $\mathrm{C}_{\mathrm{p}}$ & $\mathrm{J} / \mathrm{kg}-\mathrm{K}$ & 2000 & 1006.43 \\
\hline $\begin{array}{l}\text { Thermal } \\
\text { Conductivity }\end{array}$ & $\mathrm{W} / \mathrm{m}-\mathrm{K}$ & 0.1 & 0.0242 \\
\hline Viscosity & $\mathrm{kg} / \mathrm{m}-\mathrm{s}$ & 0.000818 & $1.7894 \mathrm{e}-05$ \\
\hline Surface Tension & $\mathrm{N} / \mathrm{m}$ & \multicolumn{2}{|c|}{0.0169} \\
\hline $\begin{array}{l}\text { Thermal } \\
\text { Expansion coeff. }\end{array}$ & $1 / \mathrm{K}$ & 0.00129 & \\
\hline Molecular Weight & $\mathrm{kg} / \mathrm{kmol}$ & 74 & 28.966 \\
\hline
\end{tabular}

Table 2. Acrylic properties

\begin{tabular}{|l|c|c|}
\hline Property & Units & Acrylic \\
\hline Density & $\mathrm{kg} / \mathrm{m}^{3}$ & 1170 \\
\hline $\mathrm{C}_{\mathrm{p}}$ & $\mathrm{J} / \mathrm{kg}-\mathrm{K}$ & 1466 \\
\hline Thermal Conductivity & $\mathrm{W} / \mathrm{m}-\mathrm{K}$ & 0.21 \\
\hline
\end{tabular}

The mesh for the model without the tank wall, shown in Fig. 3, is refined at the fluid boundaries in order to resolve the convective boundary layers. The mesh is uniform otherwise, since during sloshing the interface is moving inside the tank and does not allow to select a region for refinement like in a stationary interface case. The grid for this case consists of 2,059,200 cells. Central tank axis of computational geometry is aligned with $\mathrm{x}$ axis, as shown in Fig. 3. The front view shown in Fig. 3, as well as, all contour plots presented in this paper show a view of the tank center plane with positive y direction to the right and positive $z$ direction towards the viewer. The grid for the model with the tank wall is shown in Fig. 4. It is similar to the previous grid, but is slightly larger, consisting of 2,573,165 cells. A special grid was created to run the Large Eddy Simulation (LES) cases. It is refined throughout the domain and near the tank walls. The LES grid, consists of 9,576,315 cells, as shown in Fig. 5

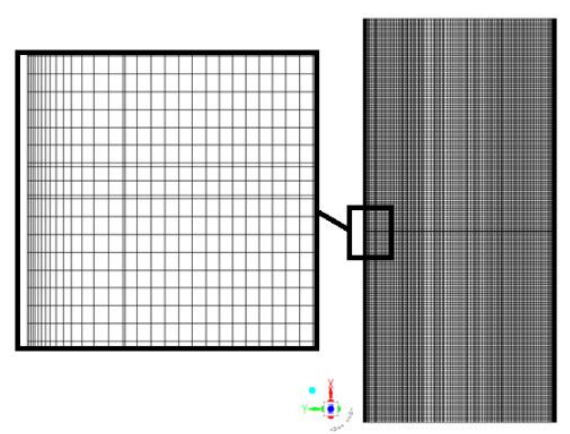

Front View

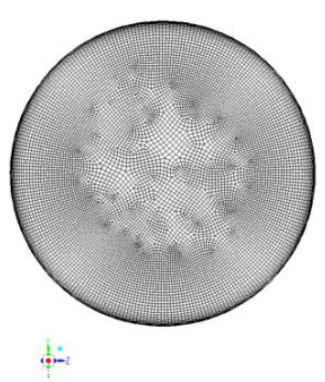

Top View
Figure 3: Computational mesh without the tank wall $(2,059,200$ cells $)$ 


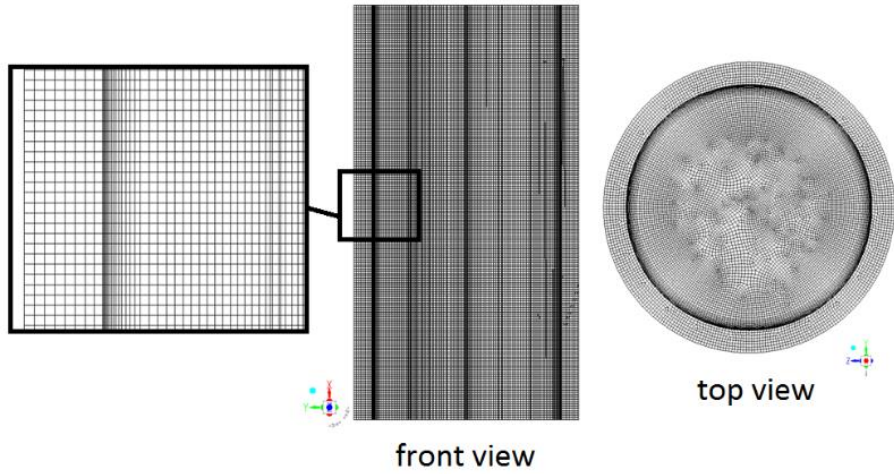

Figure 4: Computational mesh with the tank wall $(2,573,165$ cells $)$

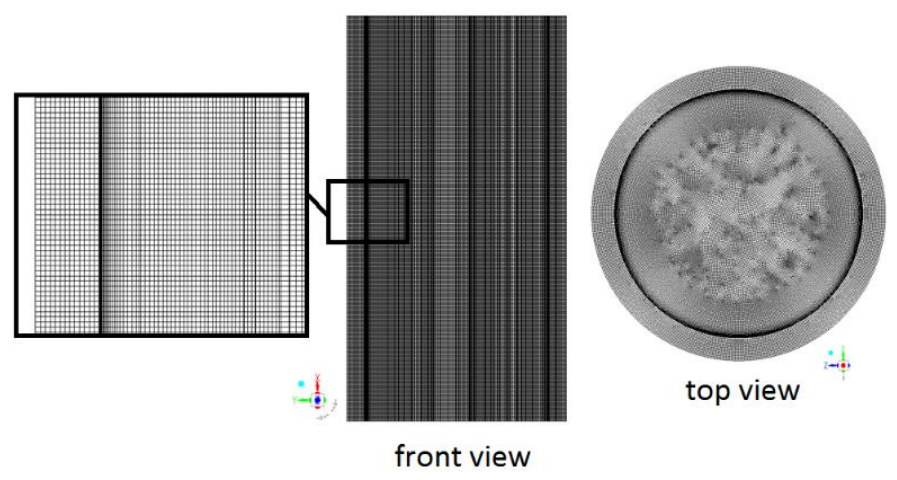

Figure 5: Computational mesh with the tank wall used in the LES case $(9,576,315$ cells $)$

\section{Solution methods}

The simulations were performed using version 17 of the ANSYS Fluent CFD code [20]. The full 3D geometry was modeled. The methods described below were used when the RANS k- $\omega S S T$ turbulence model was utilized.

The Second Order Upwind scheme was used to discretize the turbulence, energy, and momentum equations (cell values). The PISO scheme was used for the pressure-velocity coupling (cell values). The Least Squares Cell Based scheme was used for the gradient calculations (face values). The Body Force Weighted scheme was used for the pressure interpolation (face values). The Point Implicit (Gauss-Seidel) linear equation solver with the Algebraic Multi-Grid (AMG) method was used to solve the linearized systems of equations. The First Order Implicit temporal discretization scheme was used with the explicit VOF model with a time step size equal to $1 \times 10^{-4}$ seconds. The Geometric Reconstruction scheme was used to discretize the VOF equation.

Similar methods were used with the LES model, except the Bounded Central Differencing scheme was used to discretize the momentum equation (cell values). The Bounded Second Order Implicit temporal discretization scheme was used with the explicit VOF model with a time step size equal to $5 \times 10^{-5}$ seconds. The Compressive scheme was used to discretize the VOF equation.

The convergence criteria were set to $1 \times 10^{-4}$ for all of the equations except the energy equation, for which it was set to $1 \times 10^{-6}$.

\section{RESULTS AND DISCUSSION}

\section{Obtaining Initial Conditions}

In order to obtain initial conditions for sloshing, two simulations were ran with the Sharp Interface multiphase model from -30 seconds (time at which fluid temperature distribution was reported by Himeno et al. [1]) to 0 seconds (beginning of sloshing). The Sharp Interface model was selected, since the interface is flat and stationary between -30 and 0 seconds, and since this model doesn't produce spurious velocities at the interface, as the VOF model does.

Two different initial wall temperature profiles were tested, since only the initial fluid temperature profile and no wall temperatures were available from the experiment, In the first case, it was assumed that the initial wall temperatures at -30 seconds are matching the fluid temperatures at the same axial location. In the second case, the initial tank wall temperatures were uniformly set to match the ambient temperature. In both cases, the initialization simulations continued for 30 seconds and the temperature and velocity fields at the end of each case were used as initial conditions for sloshing cases that were run with the VOF model.

\section{Initial tank wall temperature matching fluid temperature}

The results of the initialization case with the tank wall temperature set to match the fluid temperature are presented in Figs. 6-8. Figure 6 shows temperature contours at the center plane of the tank at the beginning and end of the initialization case. The stratification in the gaseous region widens after 30 seconds, while in the liquid phase it remains the same. Figure 7 shows velocity vectors at the center plane of the tank, indicating the presence of vortices near the tank wall and the interface in the gaseous region. These vortices are most likely due to a large difference in thermal conductivity between the air inside the tank and the acrylic wall. Thermal conductivities of the wall and the silicone oil are very similar. Temperature profile along the central axis of the tank (x-axis), plotted in Fig. 8, also shows widened stratification in the gaseous phase. Temperature profile in the liquid phase remains unchanged, as shown in Fig. 8.

Initial tank wall temperature matching ambient air temperature

The results of the initialization case with the tank wall temperature set to match the temperature of the ambient air are presented in Figs. 9-11. Figure 9 shows temperature contours at the center plane of the tank at the beginning and end of the initialization case. After 30 seconds, the stratification in the gaseous region becomes wider. Fig 10 indicates that the stratification in the liquid phase becomes wider also, due to mixing of the liquid by the vortices formed at the bottom of the liquid region near the tank walls. Fig. 10, also, indicates presence of vortices near the tank wall and interface in the gaseous region. Again, these vortices are most likely due to a large difference in thermal conductivity between the air inside the tank and the acrylic wall. Temperature profile along the central axis of the tank (x-axis), plotted in Fig. 11, also shows widened stratification in both phases. 


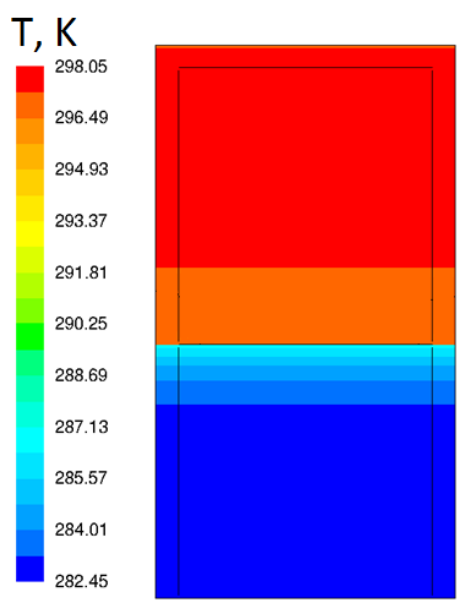

- 30 seconds

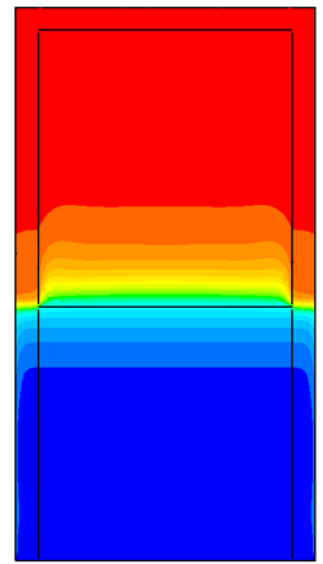

0 seconds

Figure 6. Temperature at the center plane of the tank at -30 (from experiment) and 0 seconds (from CFD) prior to sloshing (Sharp Interface model): initial tank wall temperature matching the fluid temperature
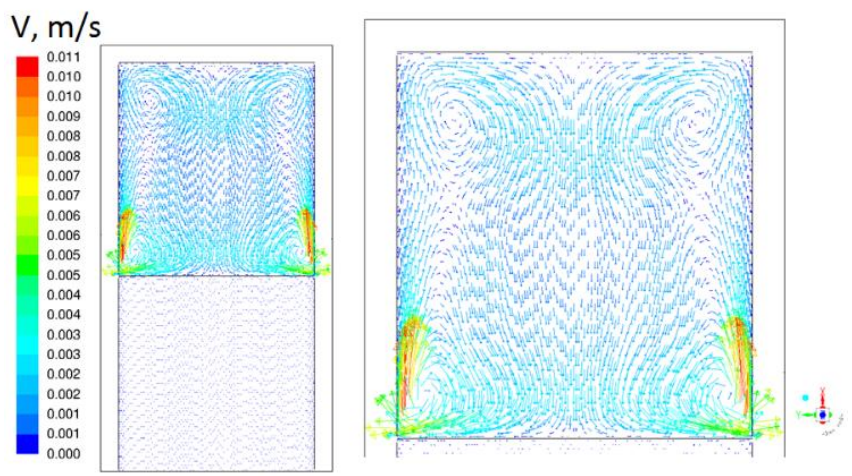

Figure 7: Velocity vectors at the center plane of the tank at 0 seconds prior to sloshing (Sharp Interface model): initial tank wall temperature matching the fluid temperature

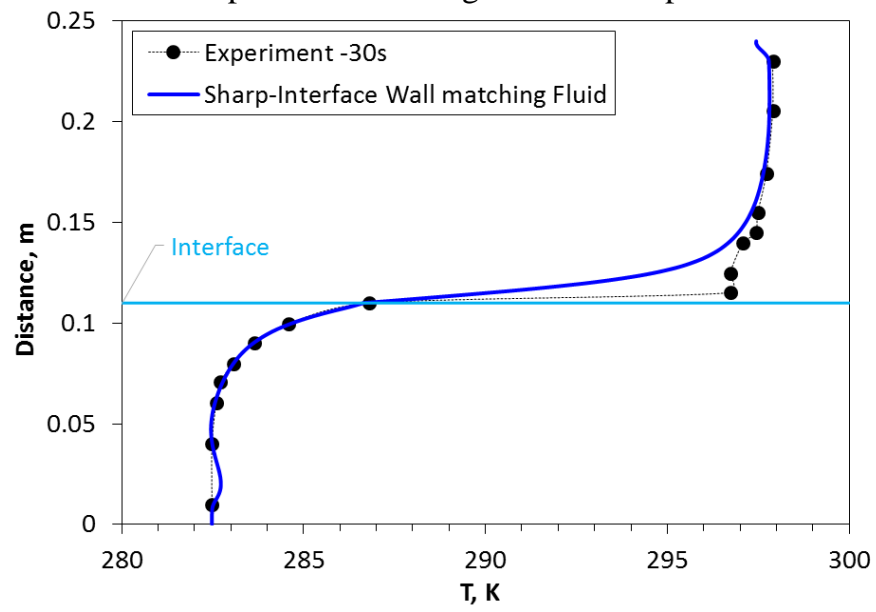

Figure 8. Temperature along the central axis of the tank at -30 (from experiment) and 0 seconds (from CFD) prior to sloshing (Sharp Interface model): initial tank wall temperature matching the fluid temperature

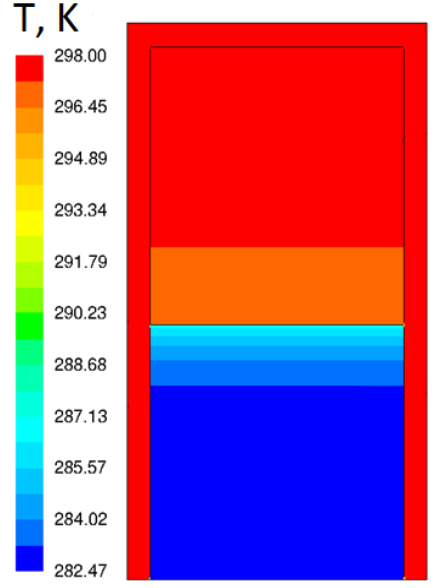

- 30 seconds

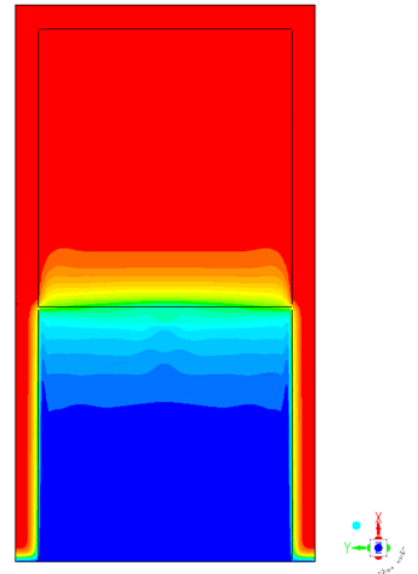

0 seconds
Figure 9. Temperature at the center plane of the tank at -30 (from experiment) and 0 seconds (from CFD) prior to sloshing (Sharp Interface model): initial tank wall temperature matching the temperature of the ambient air

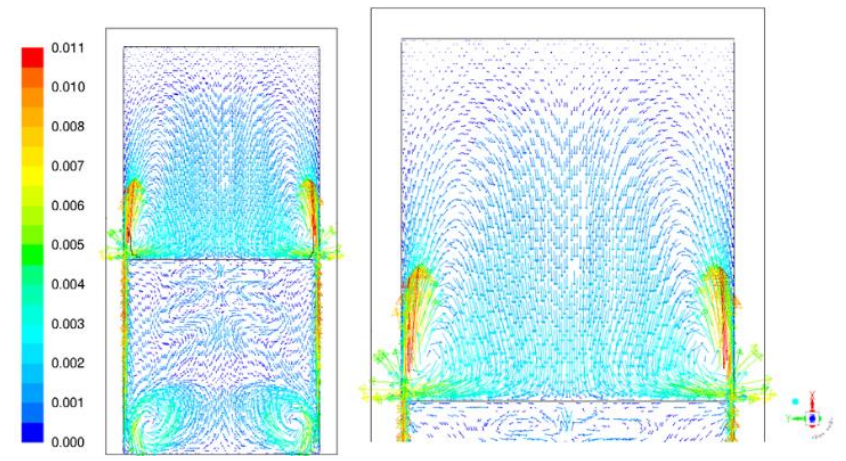

Figure 10 . Velocity vectors at the center plane of the tank at 0 seconds prior to sloshing (Sharp Interface model): initial tank wall temperature matching the temperature of the ambient air

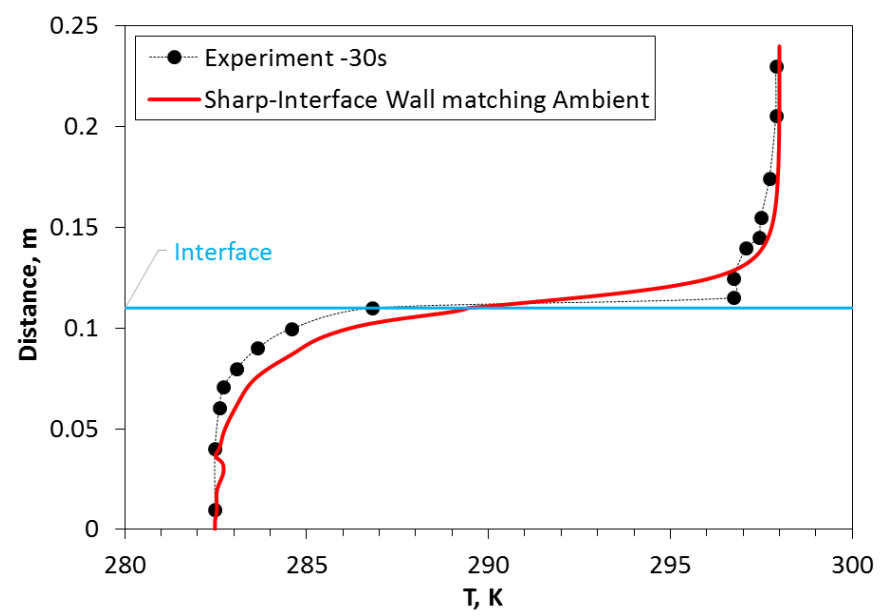

Figure 11. Temperature along the central axis of the tank at -30 (from experiment) and 0 seconds (from CFD) prior to sloshing (Sharp Interface model): initial tank wall temperature matching the temperature of the ambient air 


\section{Sloshing}

To assess effect of grid refinement on sloshing predictions, simulations using computational meshes shown in Figs. 4 and 5 were conducted with the $k$ - $\omega S S T$ model. The resulted tank pressure evolutions are shown in Fig. 12. As can be seen in Fig. 12, significant increase in a number of computational cells produced very little difference in the predicted tank pressure. The smaller size mesh $(2,573,165$ cells $)$ was used in this study with the $k-\omega S S T$ model.

A contact angle of 90 degrees was assumed between silicone oil and the wall, since information on the actual value was not available and changing the value to 0 degrees had little effect on the tank pressure.

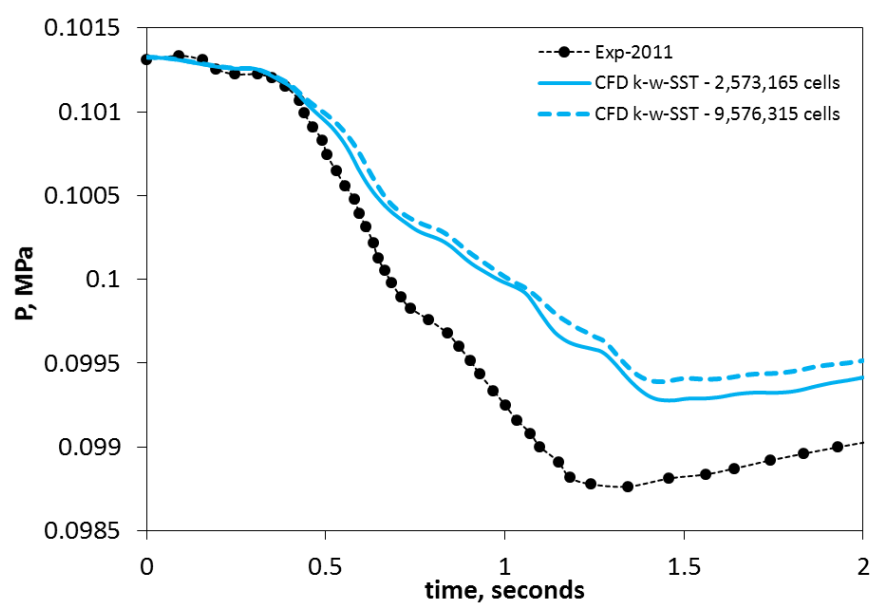

Figure 12. Pressure evolution in the tank during sloshing: Effect of computational mesh

Different factors that affect the pressure drop during sloshing include: turbulence model, turbulence level at the interface; initial and boundary conditions. The effects of these factors are discussed below.

\section{Effect of conjugate heat transfer}

First the effect of conjugate heat transfer is studied with the $k$ - $\omega S S T$ model. Pressure evolutions in the tank during sloshing predicted by the conjugate and no wall models are compared with the experimental data in Fig. 13. In the experiment the pressure was measured on the inner surface of the tank cap in the gaseous region. Computational results show values of pressure averaged in the gaseous phase.

Despite the fact that the model w/o the tank wall is in a better agreement with the experimental pressure values compared to the conjugate model, it fails to predict the increase in tank pressure after 1.5 seconds of sloshing. The conjugate model picks up the slope of the pressure curve in the beginning and end of the sloshing period better compared to the model w/o the wall. This model also correctly predicts the increase in tank pressure after 1.5 seconds of sloshing. This could be explained by the fact that the tank pressure increase at the end of sloshing is caused by heat transfer from the hot tank wall to the cool gas after the interface movement subsides. This emphasizes the importance of including the tank wall in calculations to allow more accurate tank pressure prediction.

\section{Effect of turbulence modeling}

In this section, the results of four different turbulence models, namely, the $k$ - $\omega S S T$, Realizable k-epsilon (RKE), Transition-SST and Large Eddy Simulation (LES), are compared to the results of the Laminar model and the experiment. The same computational mesh, shown in Fig. 4, was used with all the models, except for the LES model. The same time step size of $1.0 \mathrm{e}-4$ seconds was used with all RANS models.

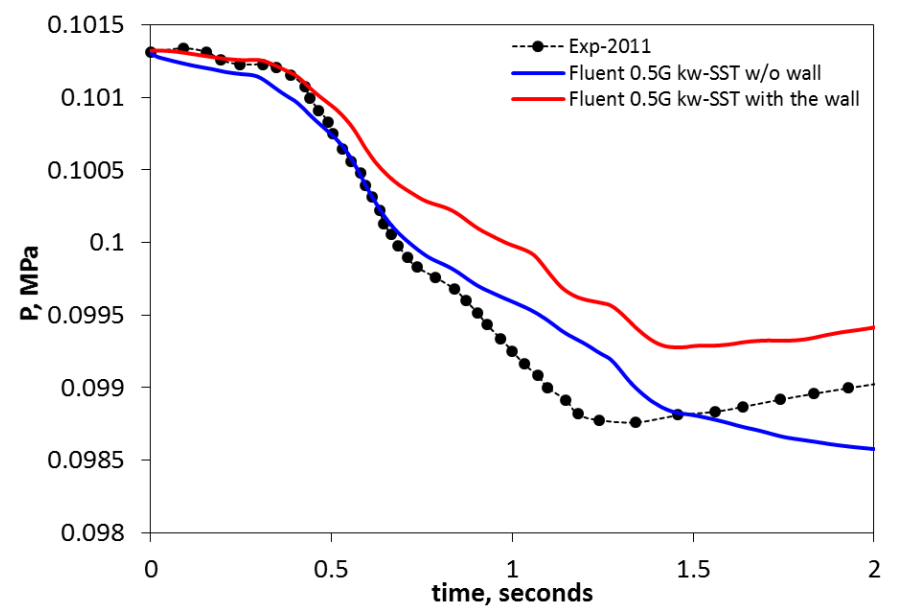

Figure 13. Pressure evolution in the tank during sloshing: Effect of including conjugate heat transfer in the tank wall

The refined computational mesh, shown in Fig. 5, was used with the LES model. The reduced time step size of 5.0e-5 seconds was used with the LES model. The resulting pressure evolutions in the tank during sloshing are compared to the experimental data in Fig. 14, where it is shown that out of three RANS models the $k$ - $\omega S S T$ model matches the trend of the pressure evolution curve the best. However, it still over-predicts the values of the tank pressure after 0.5 seconds of sloshing compared to the experimental ones. It is important to note that when the tank wall is included in simulation the $k-\omega S S T$ model predicts the pressure increase in the tank after 1.5 seconds of sloshing. This pressure increase was not predicted by this model in the case without the tank wall, as shown in Fig. 13. The Laminar model predicts the tank pressure values which are very similar to the ones predicted by the $k$ - $\omega S S T$ model. The results of the RKE model do not agree with the trend and values of the experimental pressure curve. This model under-predicts experimental pressure for the first 0.8 seconds of sloshing and over-predicts it for the rest of sloshing. The RKE model, also, does not predict the tank pressure rise observed in the experiment at the end of sloshing, which is predicted by the $k-\omega S S T$ model. The Transition-SST model predicts significantly higher tank pressures between 0.5 and 2 seconds of sloshing compared to the results of the other models and experimental data. The results of the LES model presented in Fig. 14 are in the best agreement with the experimental data as compared to all other CFD models. The tank pressure values predicted by the LES model are in an 
excellent agreement with the experimental data for the first 0.6 seconds of sloshing. After 0.6 seconds the LES model somewhat under-predicts the values of the tank pressure compared to the data, however, it predicts the trend of the experimental pressure curve well. The comparison of different turbulence models showed that at this high level of acceleration, resolving large turbulence scales by using the LES model is essential for accurate prediction of the pressure evolution in the tank during sloshing.

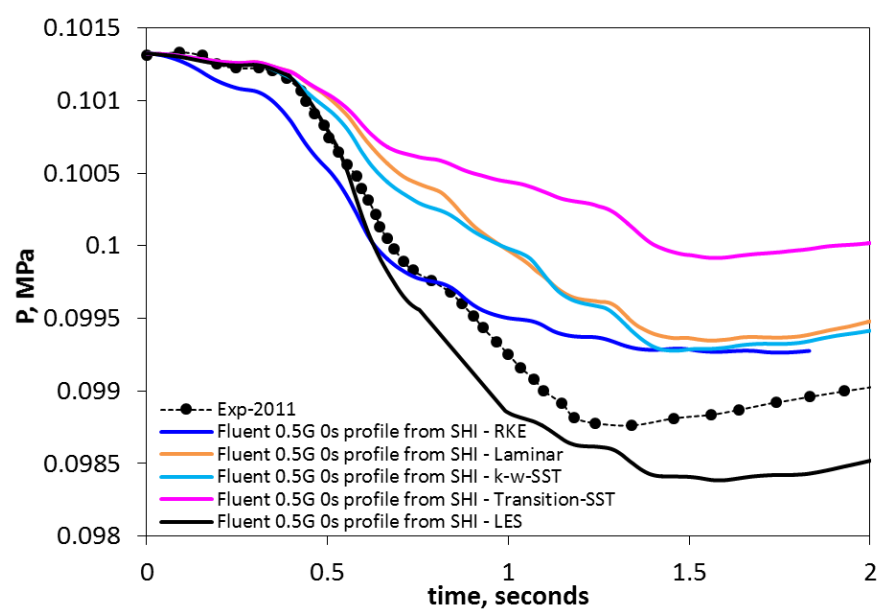

Figure 14. Pressure evolution in the tank during sloshing: Effect of turbulence model (with the tank wall)

Effect of turbulence damping at the interface with the k- $\omega$ SST model

Effect of turbulence damping at the interface was studied with the $k-\omega S S T$ turbulence model. The results of the case without turbulence damping are compared with the results of the case with turbulence damping coefficient of 100 and the experimental data in Fig. 15. The two cases result in similar tank pressures for the first 0.5 seconds of sloshing. The case with turbulence damping predicted a slower pressure drop than the case without turbulence damping between 0.5 and 1.4 seconds of sloshing and faster pressure drop after that time. Overall, the shape of the pressure curve during sloshing was better predicted in the case without turbulence damping, as compared to the case with damping, however, the case with damping resulted in lower pressures that are closer to the experimental ones at the end of sloshing.

\section{Effect of Initial Temperature Profile}

The effect of initial temperature profile before beginning of sloshing was studied by comparing the results generated by three different initial temperature profiles.

In the first one, the temperature profile reported by Himeno et al. [1] at -30 seconds (with the beginning of sloshing being 0 seconds) was applied in the fluid and in the tank wall and the initialization simulation was performed using the Sharp Interface model, as was described in the "Initial tank wall temperature matching fluid temperature" section above. The resulting temperature and velocity profiles were applied at the beginning of sloshing. This profile is called a "matching wall" profile in this study. The second profile is called a "hot wall" profile in this paper. The procedure for obtaining this profile is described in the "Initial tank wall temperature matching ambient air temperature" section above. The third profile is similar to the "matching wall" profile, but the tank wall on the liquid side of the interface was set to the coldest liquid temperature of $282.42 \mathrm{~K}$, as shown in Fig 16.

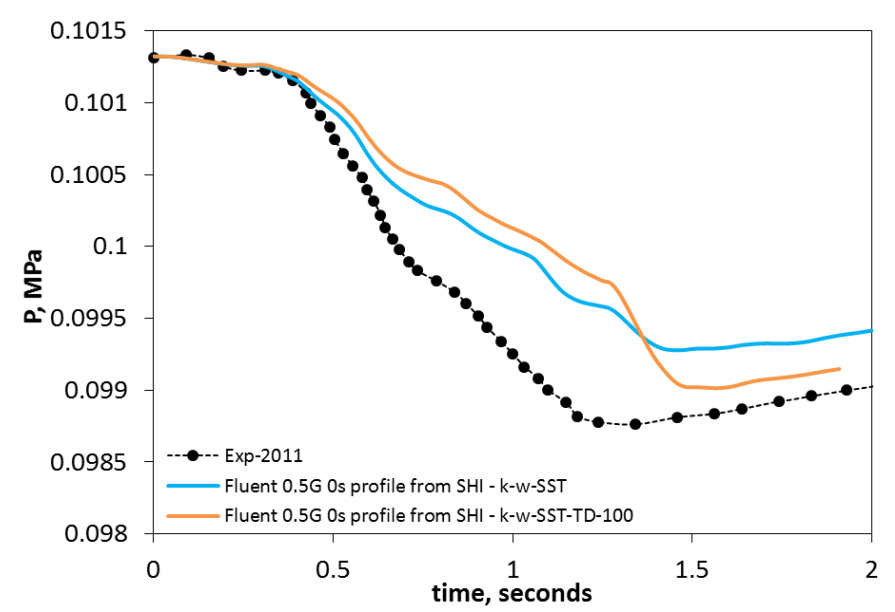

Figure 15. Pressure evolution in the tank during sloshing: Effect of turbulence damping at the interface with the $k-\omega S S T$ turbulence model (with the tank wall)

The resulting pressure evolutions in the tank generated by these three profiles applied as initial conditions are compared to the experimental data in Fig. 17. The "hot wall" initial temperature profile resulted in higher tank pressures compared to the results generated by the other two initial profiles and to the experimental data. The models with the "matching wall" and "cold wall" initial temperature profiles predicted very similar tank pressures that are lower than the results of the "hot wall" case. They were in a closer agreement with the experimental data. The result of this comparison underlines the importance of knowing the initial wall temperature profile and applying the correct initial and boundary conditions.

\section{Results of the k- $\omega$ SST model with and without the conjugate heat} transfer in the tank wall

The detailed comparison of the results of the $k-\omega S S T$ turbulence model with the conjugate heat transfer with those of the CFD study reported by Himeno et al. [2] and the experimental data [1] are presented in Figs. 18-28. The results of the $k$ - $\omega S S T$ model without the tank wall are also included in Figs. 18-28 for comparison. Both current models with and without the tank wall predict similar interface movements that match the ones captured in the experiment reasonably well, aside from the fact that the RANS models can't resolve fine details of droplet atomization.

Results of current models for interface motion, also, match the results of the Himeno et al. [2] CFD model. A comparison of temperature fields between the two current models with and without the tank wall shows that the conjugate model predicts more cooling in a layer near the interface in the beginning of sloshing, compared to the model without the tank wall (see Figs. 
18, 19). In the middle of sloshing, as shown in Figs. 20-26, the models with and without the tank wall predict similar temperatures in the gaseous region.

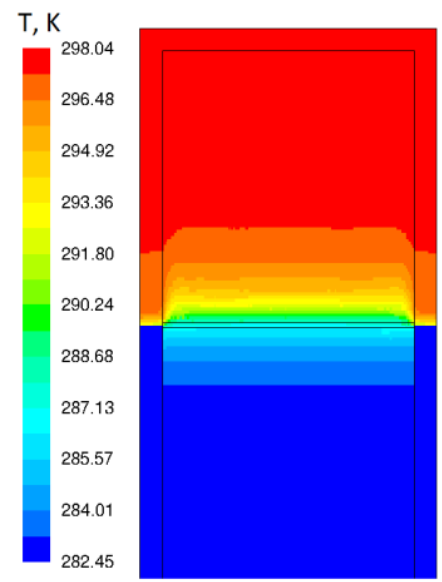

Figure 16. Temperature at the center plane of the tank at the beginning of sloshing: cold wall

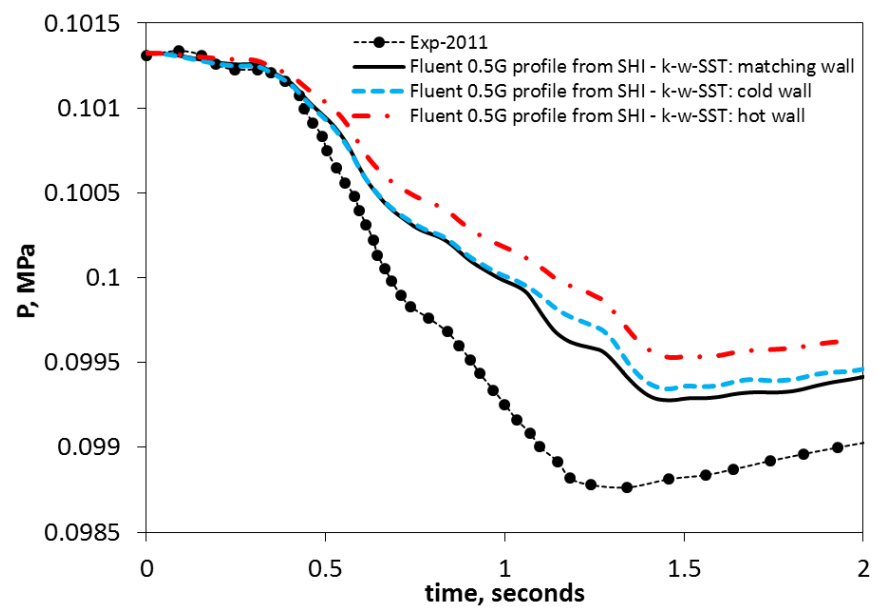

Figure 17. Pressure evolution in the tank during sloshing: Effect of initial temperature profile (with the tank wall)

At the end of sloshing, as shown in Figs. 27 and 28, the model with the tank wall predicts higher gas temperature, compared to the one without the tank wall due to heat transfer between the hot tank wall and cooler gas. Himeno et al. [2] results show higher gas temperature predictions at all times compared to the current models. Unfortunately, information on the fluid and tank wall temperature evolutions is not available from the experiment, which makes it difficult to assess accuracy of heat transfer predictions made by the CFD models.

\section{Comparison of the $k-\omega S S T$ and LES model results}

A detailed comparison among the results of the LES turbulence model with the tank wall, the results of the Himeno et al. [2] CFD case, and the experimental data are presented in Figs. 29-40. The results of the $k-\omega S S T$ model with the tank wall are included in Figs. 29-39 for comparison, as well. During the first
0.5 seconds of sloshing the $k-\omega S S T$ and LES model predict similar interface motions and tank temperature fields, as shown in Figs. 29-32. After this time, droplet breakup occurs that is better captured by the LES model which provides better agreement with the experiment, as compared to the results of the $k$ - $\omega S S T$ model. The results of the LES model for interface motion are in an excellent qualitative agreement with the experiment. The Himeno et al. [2] models' predictions for the interface dynamics match the results of the $k$ - $\omega S S T$ model and unlike the LES model do not resolve details of droplets breakup.

The LES model predicts better mixing and more cooling of the gaseous phase compared to the $k$ - $\omega S S T$ model. The CFD model of Himeno et al. [2] predicts higher gas temperatures at all times compared to the results of the current models. Unfortunately, information on the fluid and tank wall temperature evolutions is not available from the experiment, which makes it difficult to assess accuracy of CFD heat transfer predictions.

Comparison between pressure evolutions in the tank during sloshing predicted by the current models, the CFD results reported by Himeno et al. [2] and experimental data is shown in Fig. 40. The results of the current $k-\omega S S T$ and the $L E S$ models are shown. The current $k-\omega S S T$ model and the models of Himeno et al. [2] over predict the experimental values of the tank pressure at all times. The $L E S$ model is in an excellent agreement with the data for the first 0.6 seconds of sloshing and somewhat under predicts the data for the rest of the run. Overall the results of the LES model are in the best agreement with the experimental data among all the CFD models.

\section{CONCLUSIONS}

Two-phase flow and heat transfer simulations of the silicone oil sloshing experiment of Himeno et al. [2] in normal gravity were conducted using storage tank CFD model in the framework of the ANSYS Fluent CFD code. The simulations were completed at the highest level of lateral acceleration tested in the experiment with the value equal to $0.5 \mathrm{G}$. The simulations were first performed without the tank wall and then with conjugate heat transfer in the tank wall. A comparison of simulation results with and without the tank wall illustrates the inability of the model without the tank wall to predict pressure increase in the tank at the end of sloshing due to heat transfer from a warmer wall to a cooler gas. This underscores the importance of including a conjugate heat transfer analysis in CFD models used in sloshing studies.

The effects of turbulence modeling, turbulence damping at the interface, and the initial temperature profile on tank pressure evolutions were investigated. Here, the performance of the Reynolds Averaged Navier-Stokes (RANS) turbulence models was compared to the results of the Large Eddy Simulation (LES) model.

Simulation results show that the LES approach to turbulence modeling is beneficial at higher levels of lateral acceleration such as $0.5 \mathrm{G}$. At this value of lateral acceleration the initial temperature conditions in the tank wall have less effect on the tank pressure evolution during sloshing, compared to the effect of turbulence. These conclusions underline the importance of 
selecting an appropriate turbulence modeling approach, as well as applying realistic initial and boundary conditions in the simulation that match the experimental conditions.
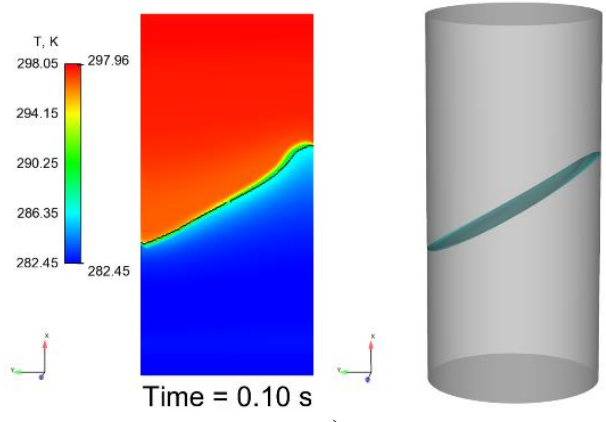

a)

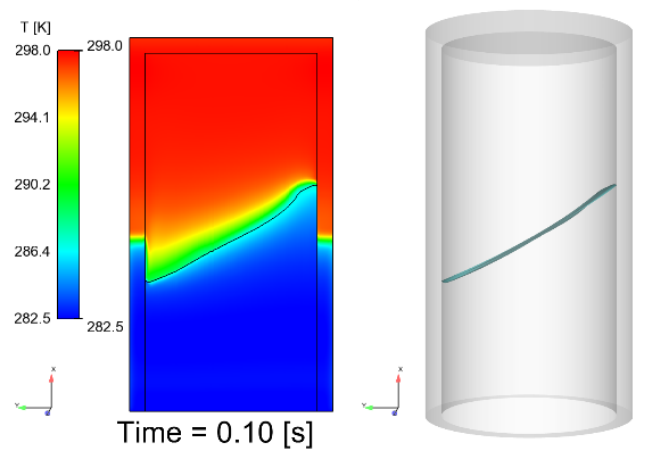

b)

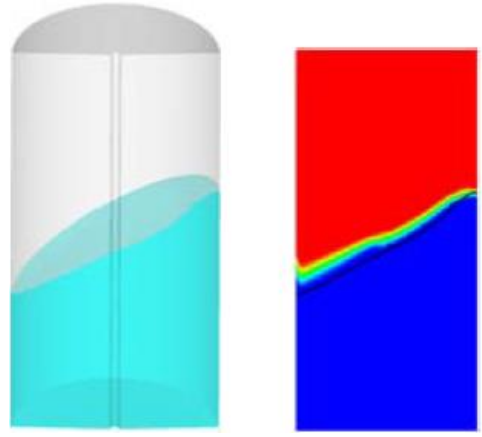

c)

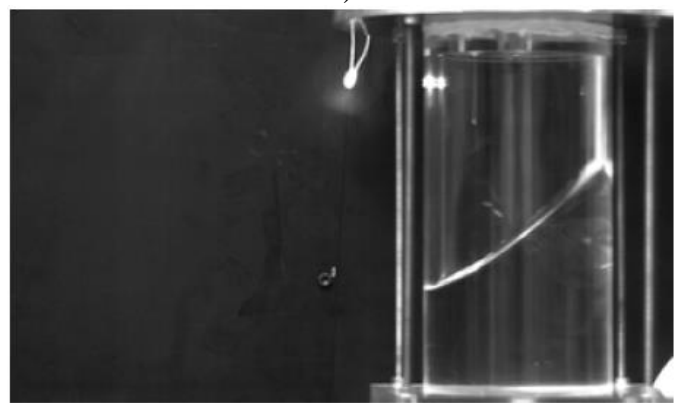

d)

Figure 18. Comparison of interface motion and temperature field at the center plane of the tank between simulations w/o tank wall (a), with the tank wall (b) and Himeno et al. [2] (c) and experiment (d) after 0.1 seconds of sloshing

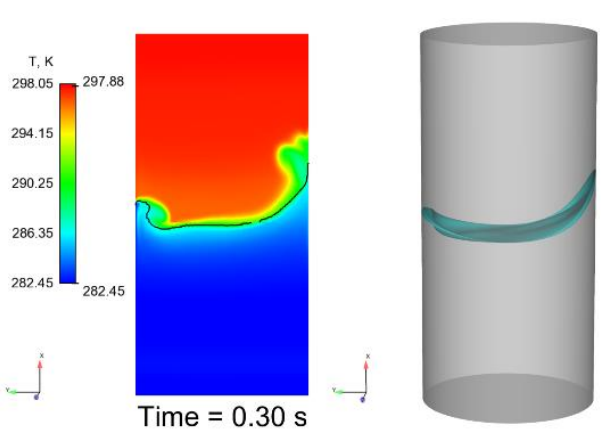

a)

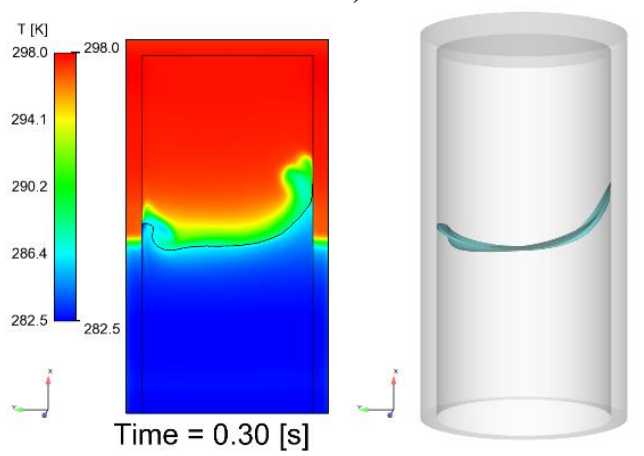

b)

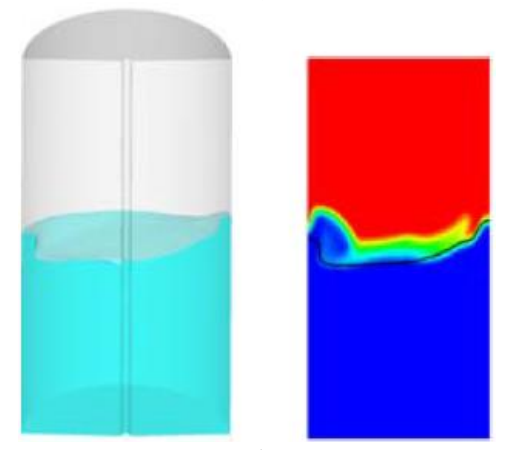

c)

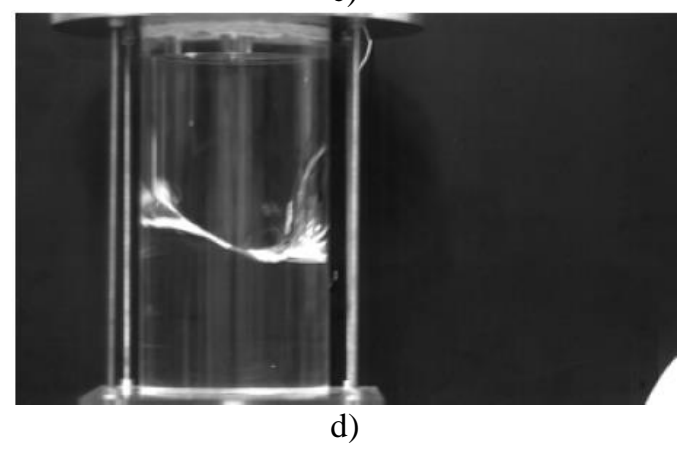

Figure 19. Comparison of interface motion and temperature field at the center plane of the tank between simulations w/o tank wall (a), with the tank wall (b) and Himeno et al. [2] (c) and experiment (d) after 0.3 seconds of sloshing 

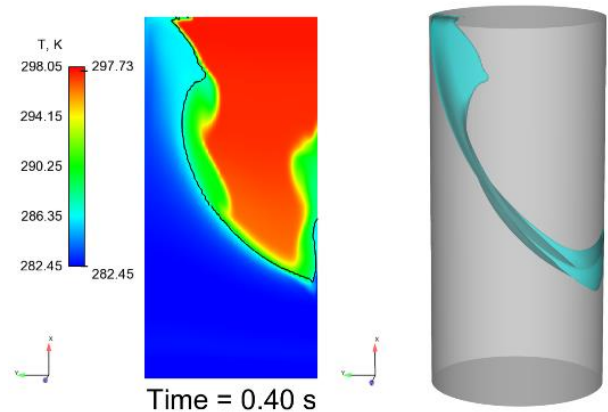

a)

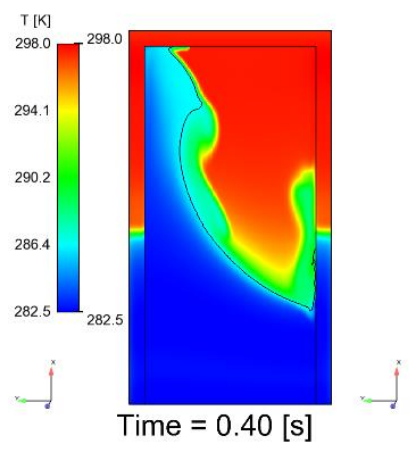

b)
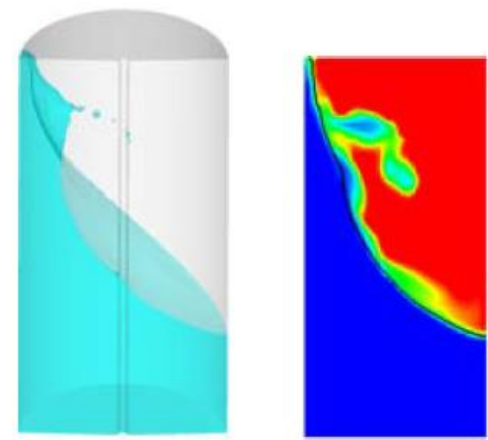

c)

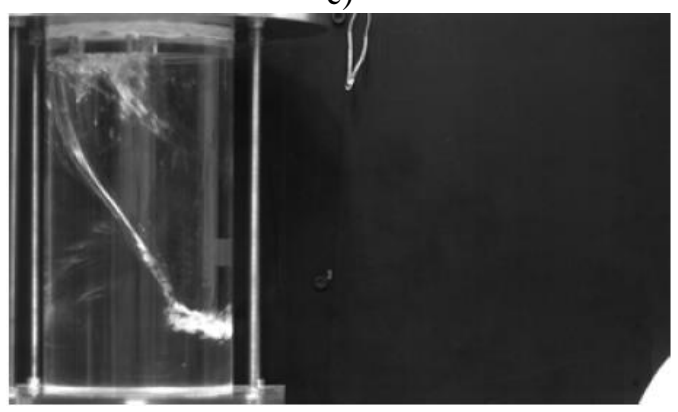

d)

Figure 20. Comparison of interface motion and temperature field at the center plane of the tank between simulations w/o tank wall (a), with the tank wall (b) and Himeno et al. [2] (c) and experiment (d) after 0.4 seconds of sloshing

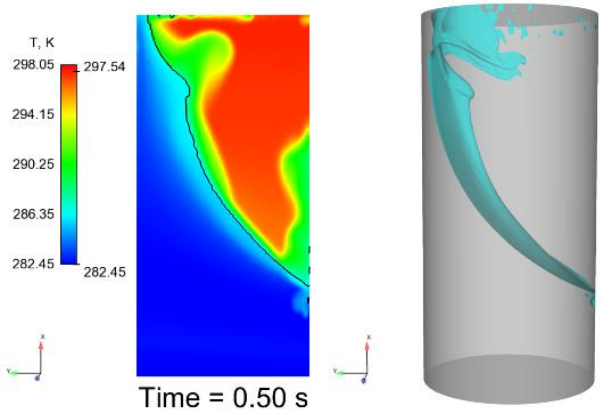

a)

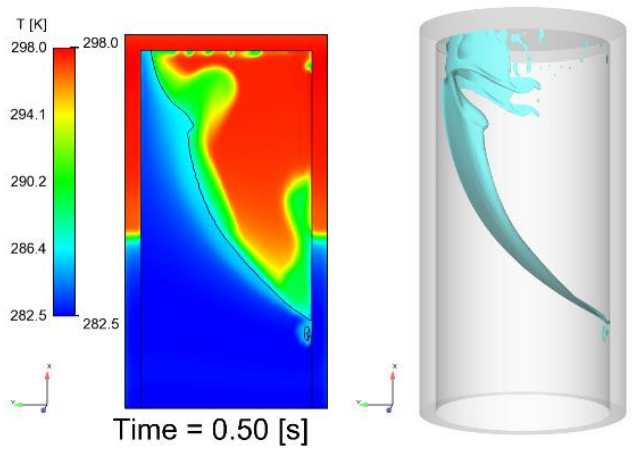

b)

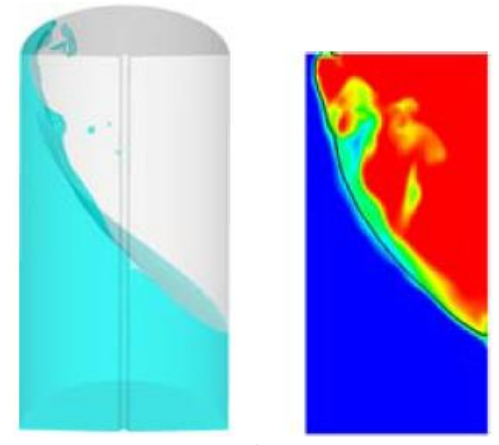

c)

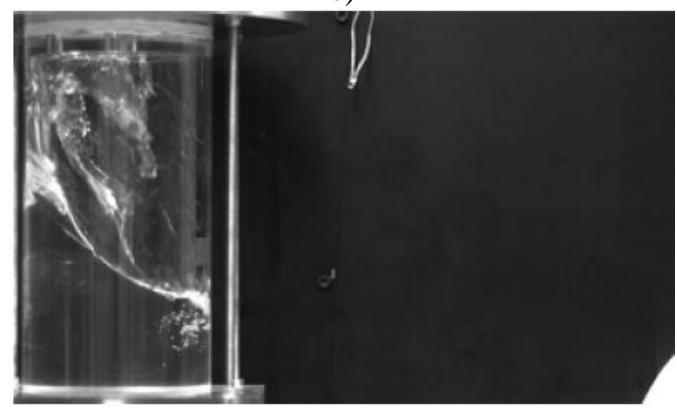

d)

Figure 21. Comparison of interface motion and temperature field at the center plane of the tank between simulations w/o tank wall (a), with the tank wall (b) and Himeno et al. [2] (c) and experiment (d) after 0.5 seconds of sloshing 

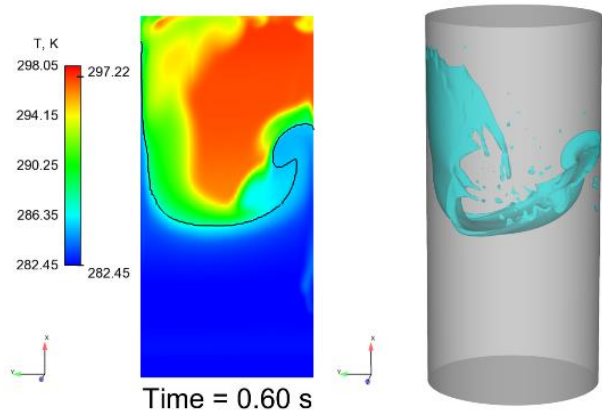

a)

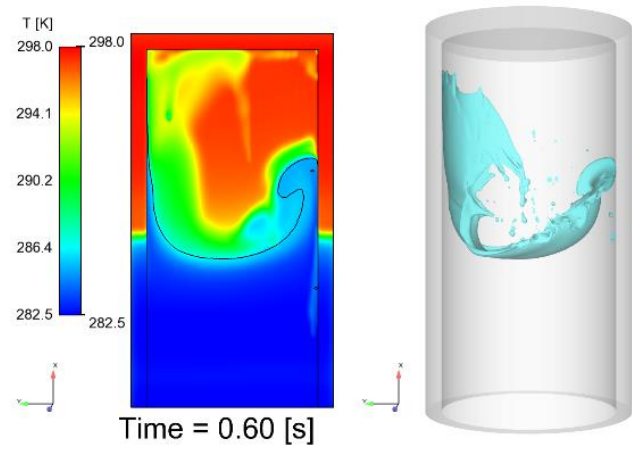

b)
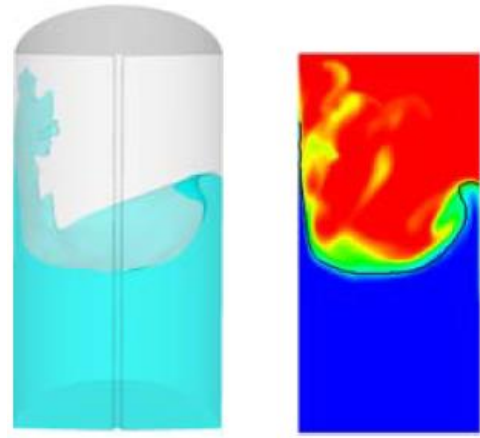

c)

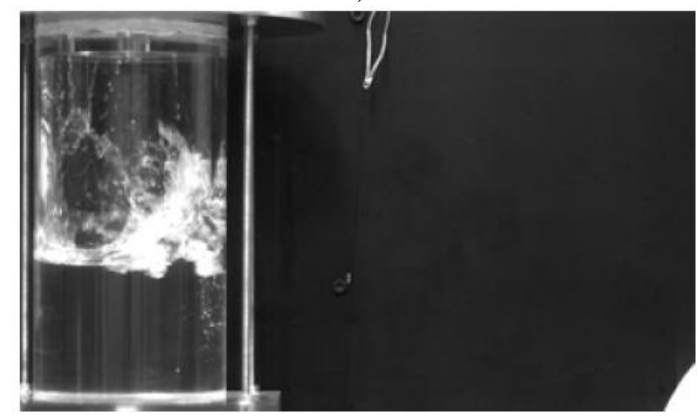

d)

Figure 22. Comparison of interface motion and temperature field at the center plane of the tank between simulations w/o tank wall (a), with the tank wall (b) and Himeno et al. [2] (c) and experiment (d) after 0.6 seconds of sloshing
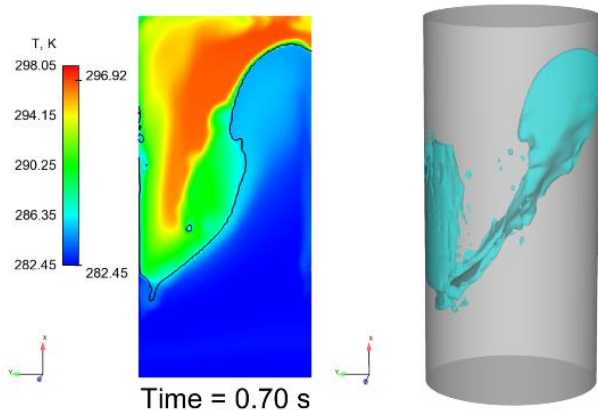

a)
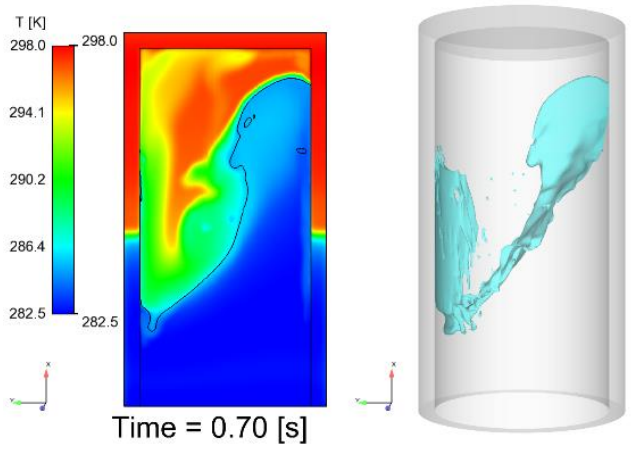

b)

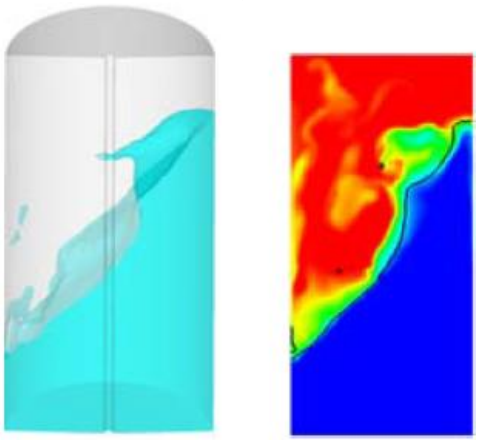

c)

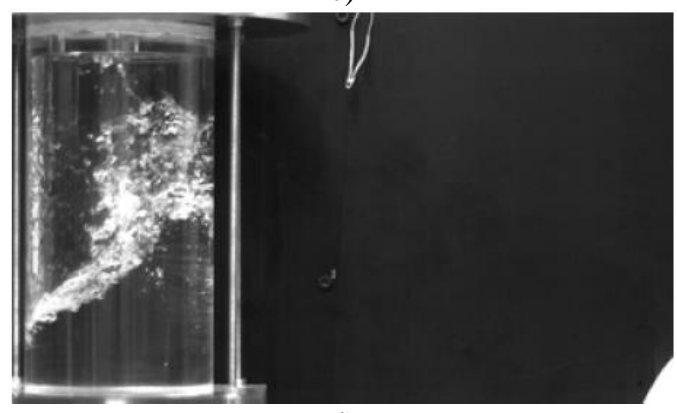

d)

Figure 23. Comparison of interface motion and temperature field at the center plane of the tank between simulations w/o tank wall (a), with the tank wall (b) and Himeno et al. [2] (c) and experiment (d) after 0.7 seconds of sloshing 

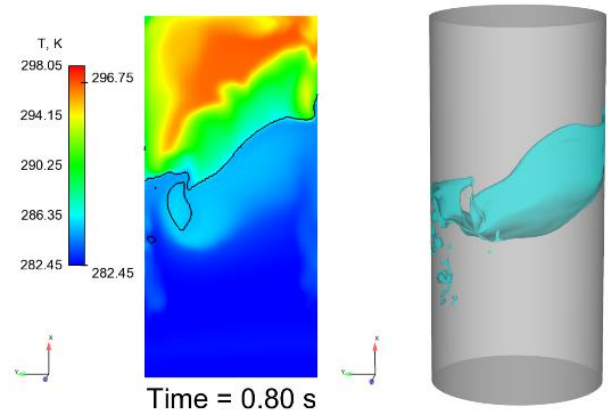

a)
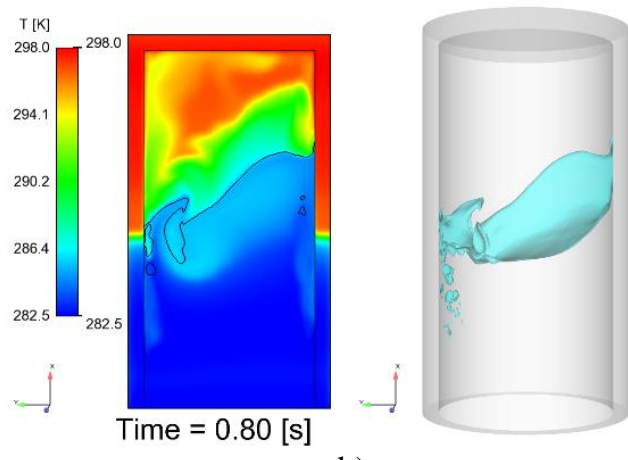

b)

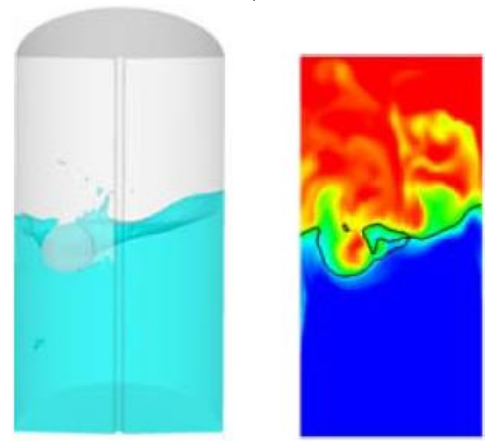

c)

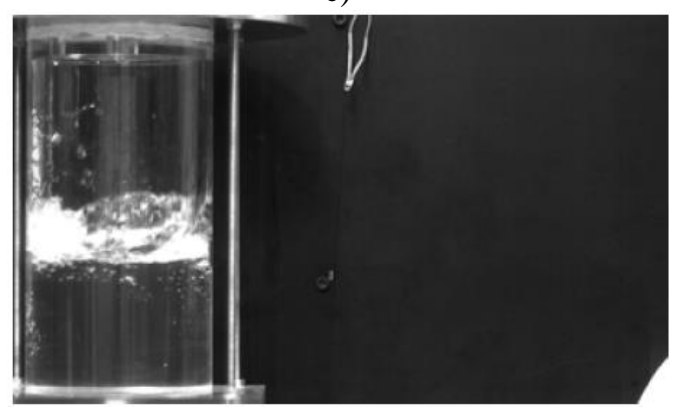

d)

Figure 24. Comparison of interface motion and temperature field at the center plane of the tank between simulations w/o tank wall (a), with the tank wall (b) and Himeno et al. [2] (c) and experiment (d) after 0.8 seconds of sloshing
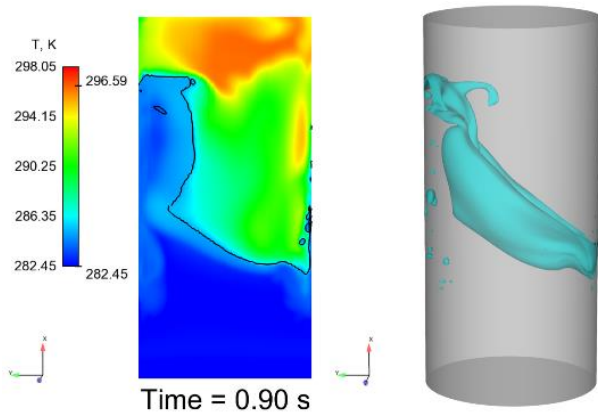

a)
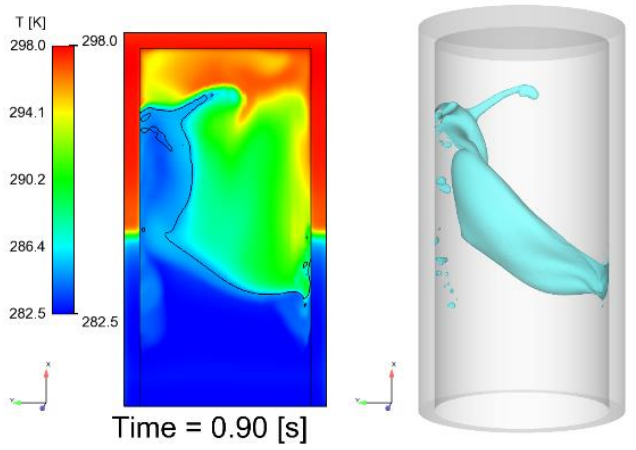

b)
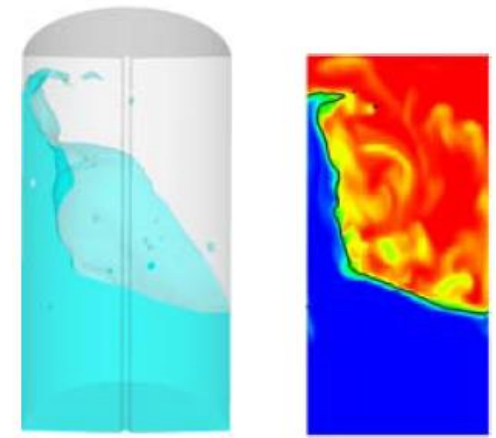

c)

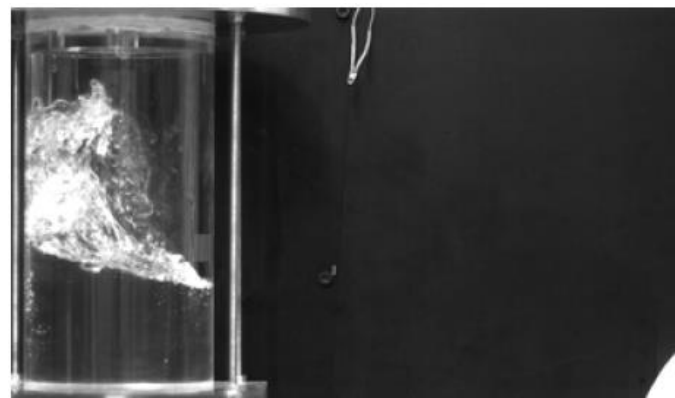

d)

Figure 25. Comparison of interface motion and temperature field at the center plane of the tank between simulations w/o tank wall (a), with the tank wall (b) and Himeno et al. [2] (c) and experiment (d) after 0.9 seconds of sloshing 

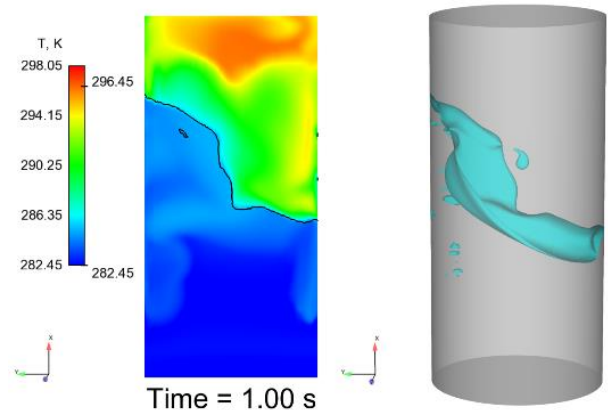

a)

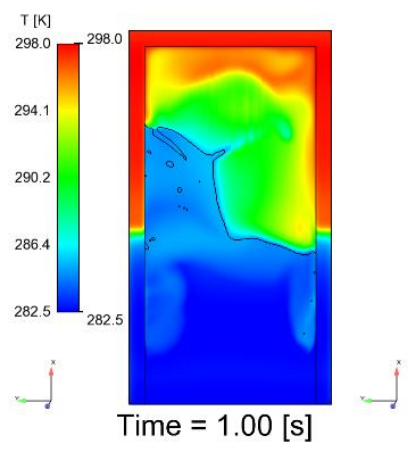

b)

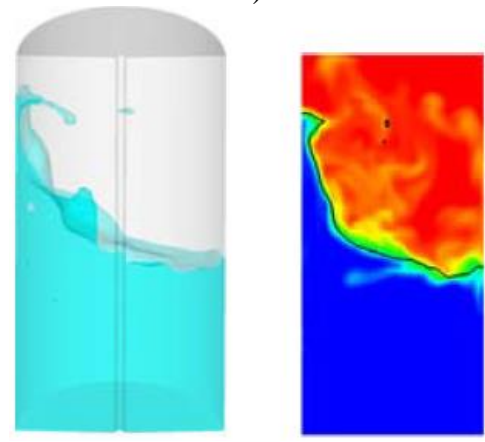

c)

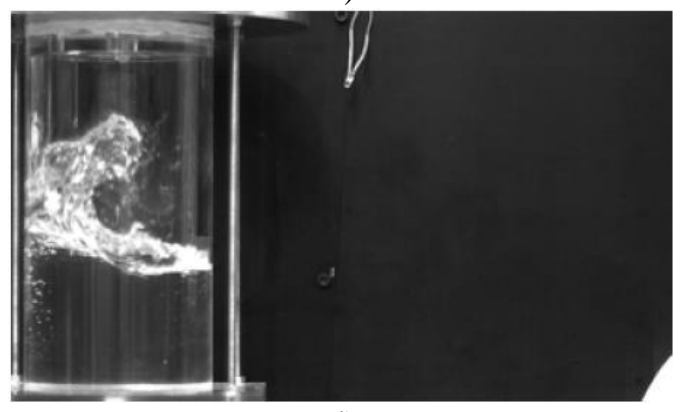

d)

Figure 26. Comparison of interface motion and temperature field at the center plane of the tank between simulations w/o tank wall (a), with the tank wall (b) and Himeno et al. [2] (c) and experiment (d) after 1.0 seconds of sloshing

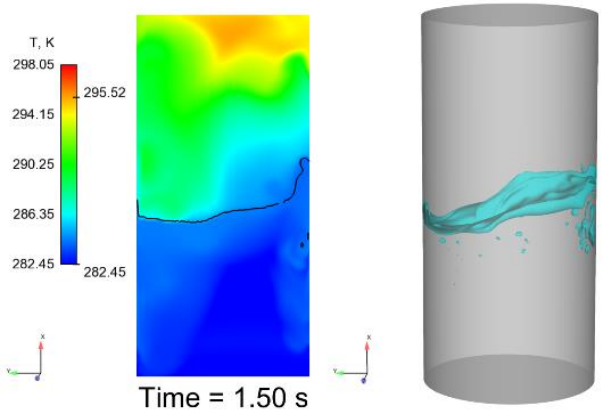

a)

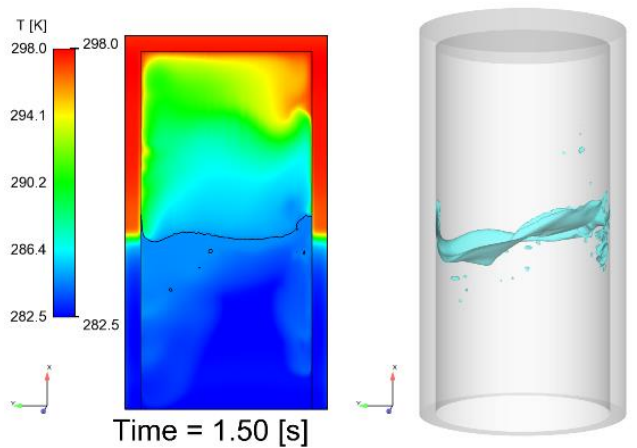

b)

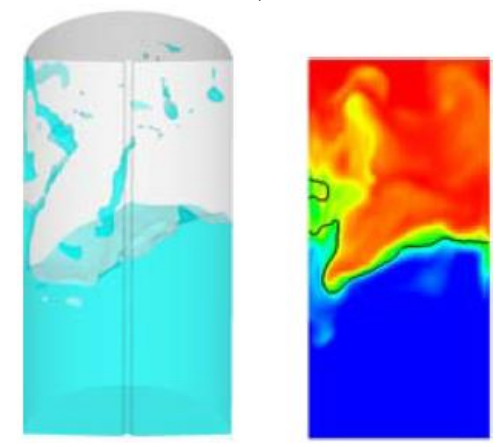

c)

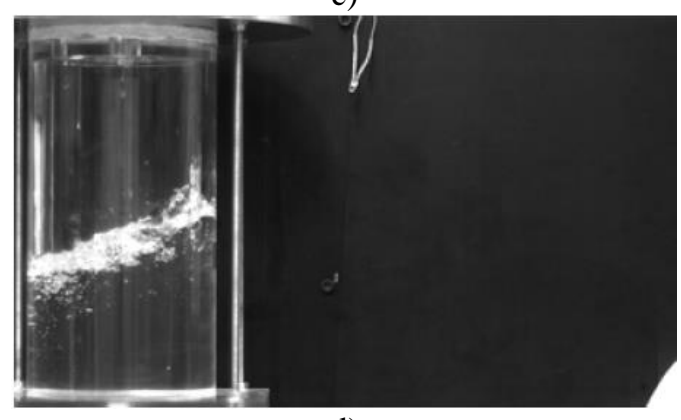

d)

Figure 27. Comparison of interface motion and temperature field at the center plane of the tank between simulations w/o tank wall (a), with the tank wall (b) and Himeno et al. [2] (c) and experiment (d) after 1.5 seconds of sloshing 

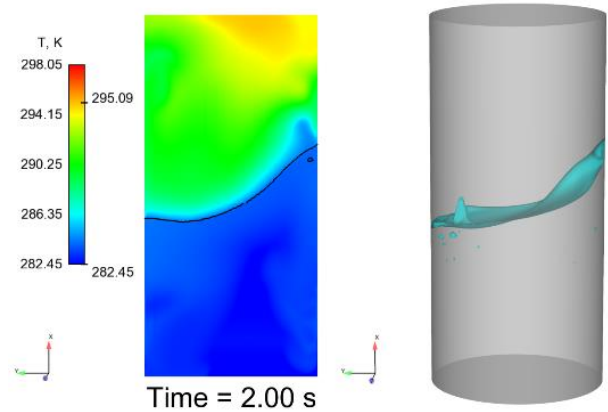

a)

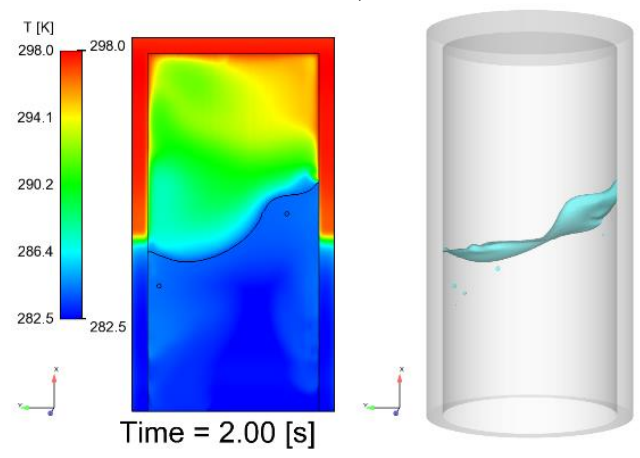

b)

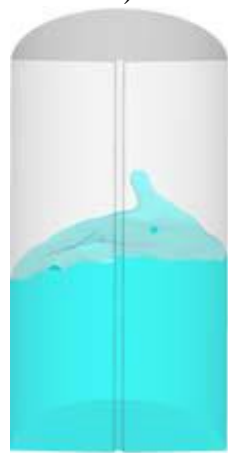

c)

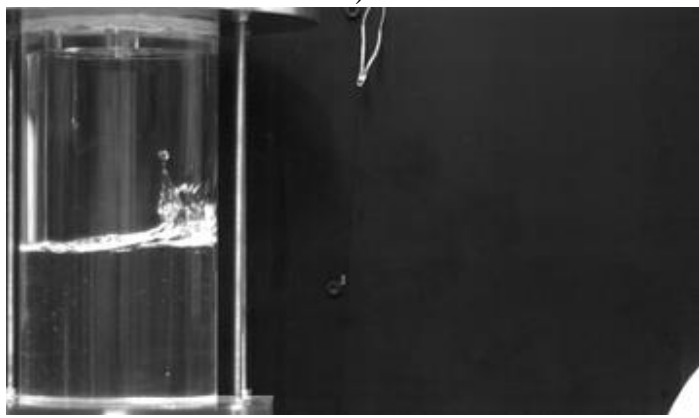

d)

Figure 28. Comparison of interface motion and temperature field at the center plane of the tank between simulations w/o tank wall (a), with the tank wall (b) and Himeno et al. [2] (c) and experiment (d) after 2.0 seconds of sloshing

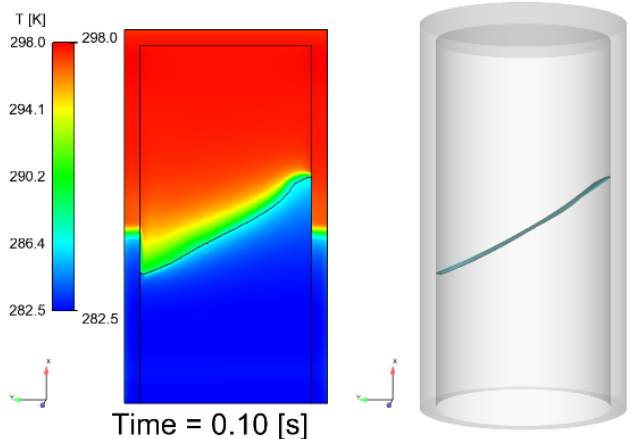

a)

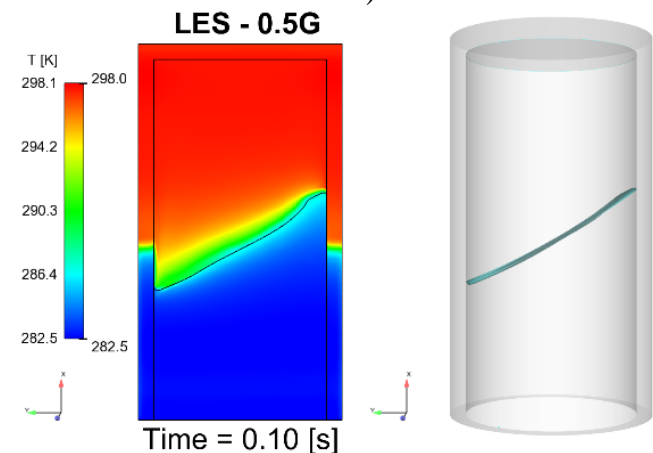

b)

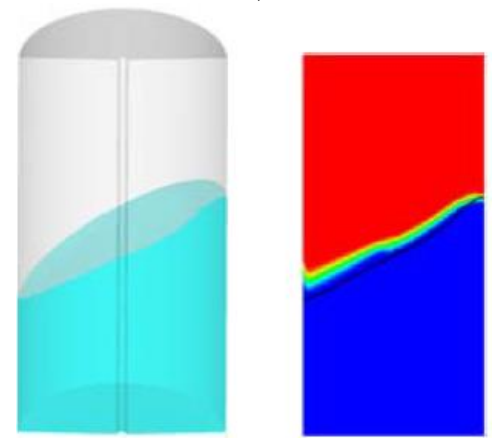

c)

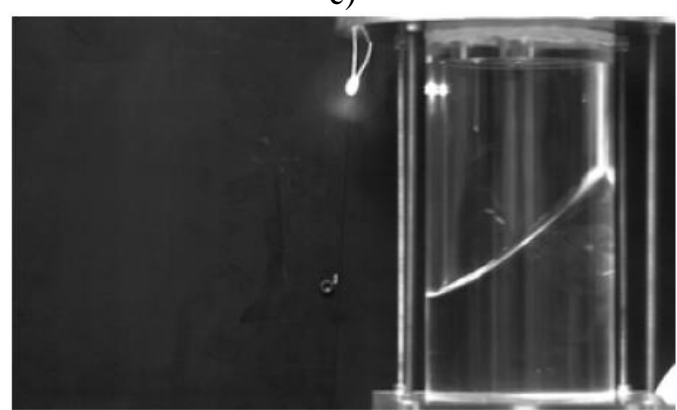

d)

Figure 29. Comparison of interface motion and temperature field at the center plane of the tank between current $k$ - $\omega S S T$ (a) and LES (b) models; results of simulation of Himeno et al. [2]

(c) and the experiment (d) after 0.1 seconds of sloshing 


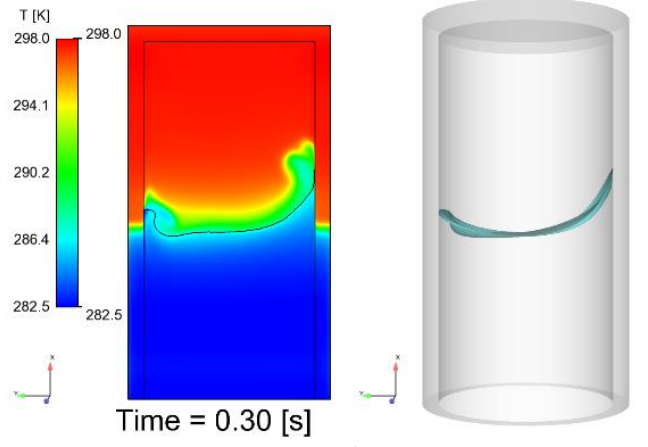

a)

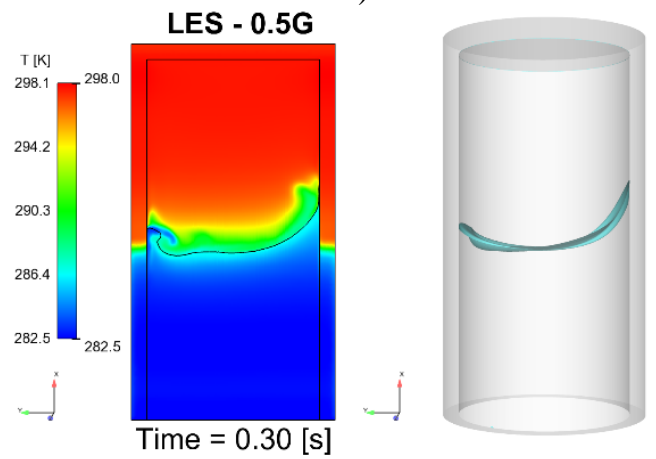

b)

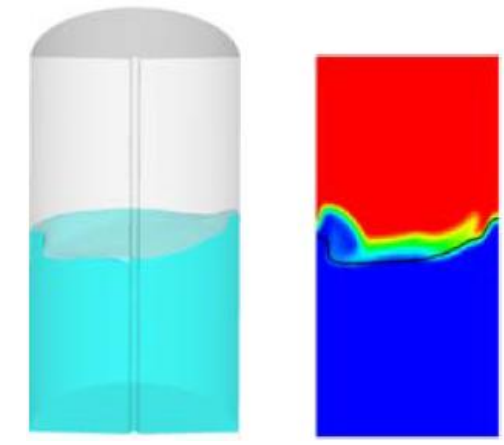

c)

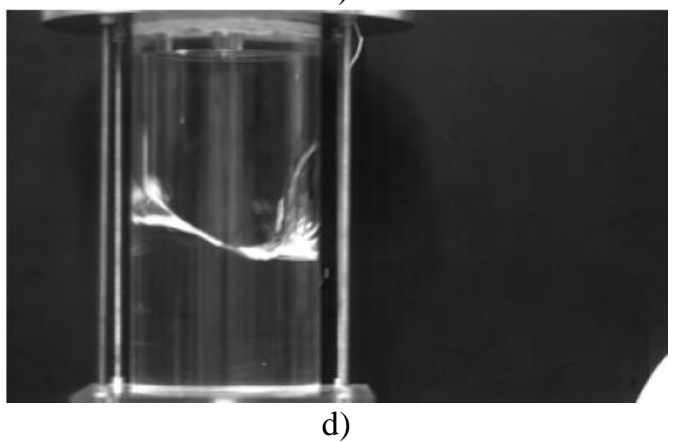

Figure 30. Comparison of interface motion and temperature field at the center plane of the tank between current $k$ - $\omega S S T$ (a) and LES (b) models; results of simulation of Himeno et al. [2]

(c) and the experiment (d) after 0.3 seconds of sloshing

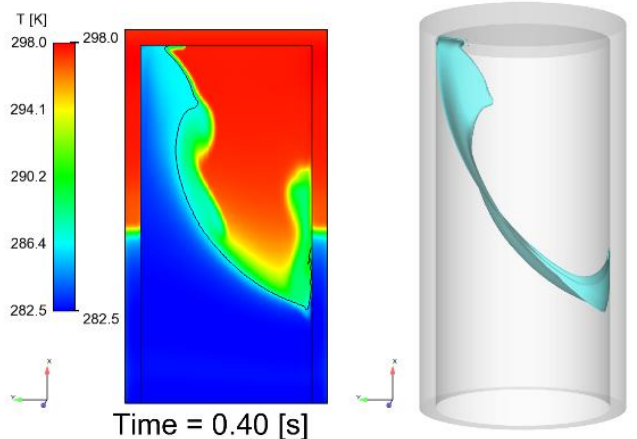

a)

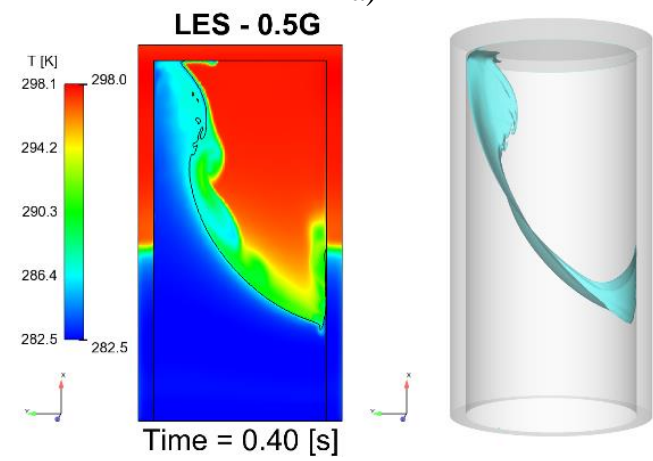

b)

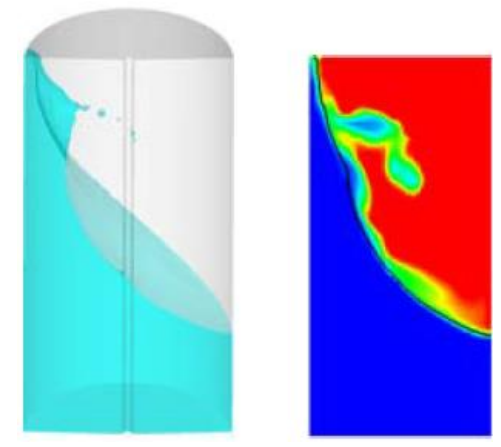

c)

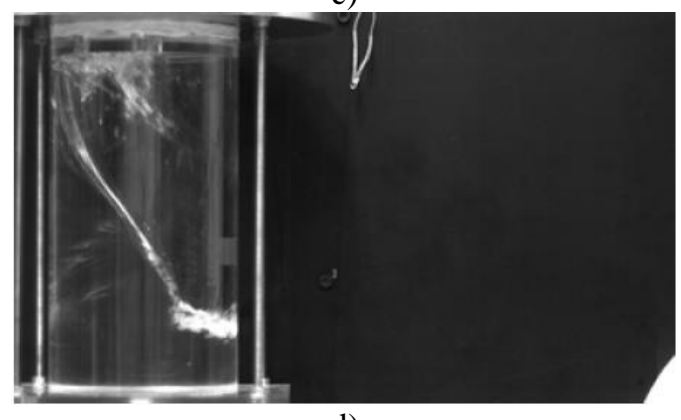

d)

Figure 31. Comparison of interface motion and temperature field at the center plane of the tank between current $k$ - $\omega S S T$ (a) and LES (b) models; results of simulation of Himeno et al. [2]

(c) and the experiment (d) after 0.4 seconds of sloshing 

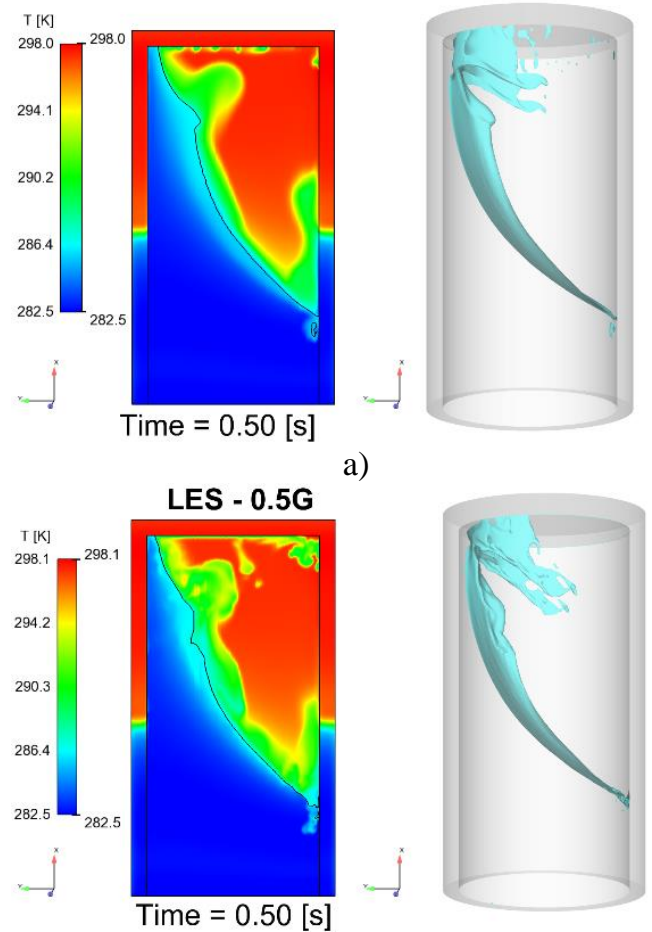

b)

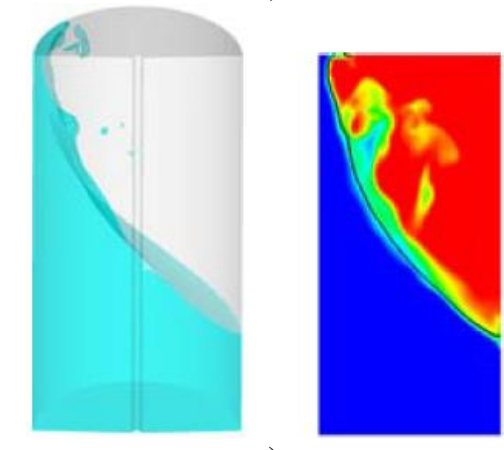

c)

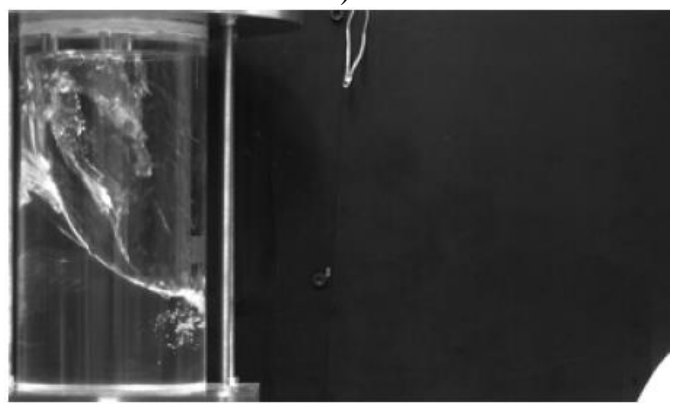

d)

Figure 32. Comparison of interface motion and temperature field at the center plane of the tank between current $k$ - $\omega S S T$ (a) and LES (b) models; results of simulation of Himeno et al. [2]

(c) and the experiment (d) after 0.5 seconds of sloshing

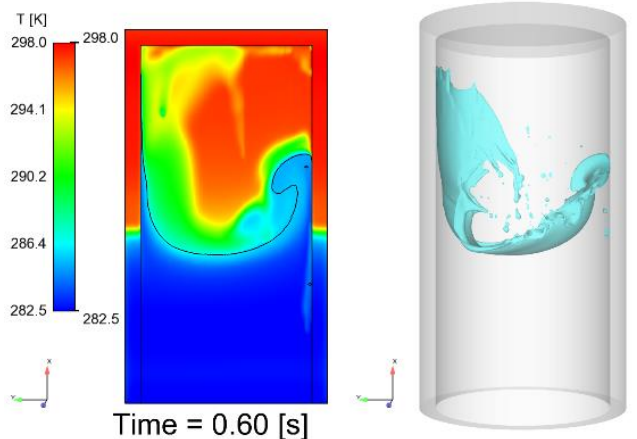

a)

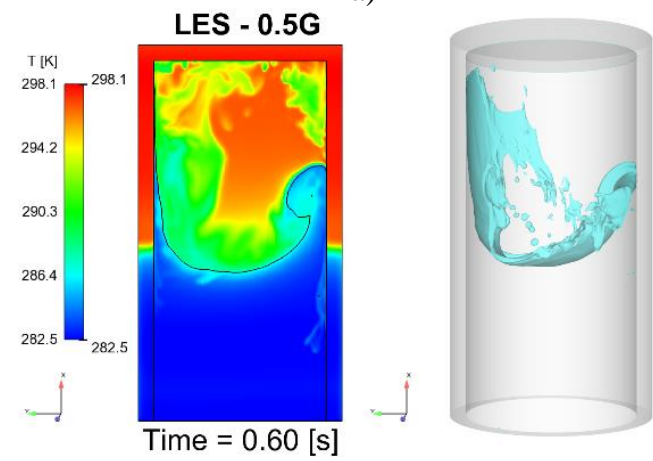

b)

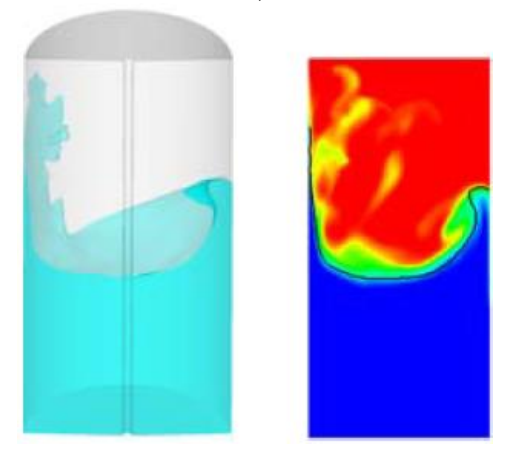

c)

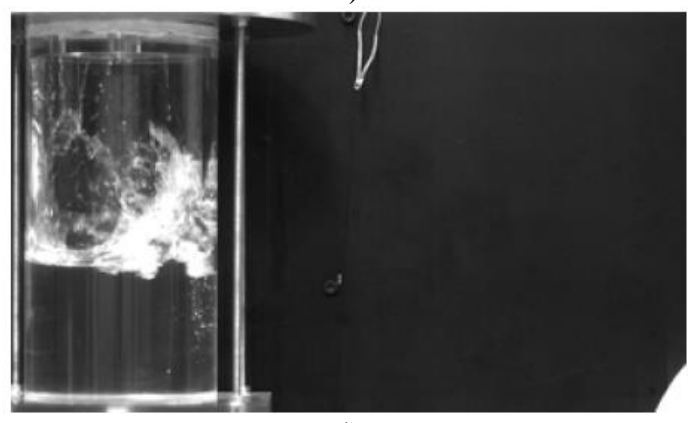

d)

Figure 33. Comparison of interface motion and temperature field at the center plane of the tank between current $k$ - $\omega S S T$ (a) and LES (b) models; results of simulation of Himeno et al. [2]

(c) and the experiment (d) after 0.6 seconds of sloshing 


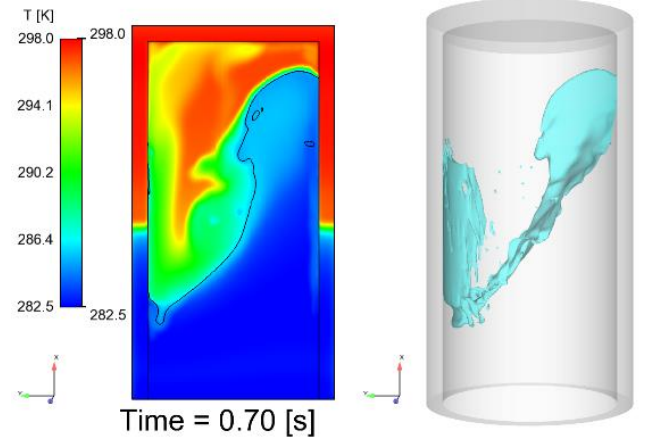

a)

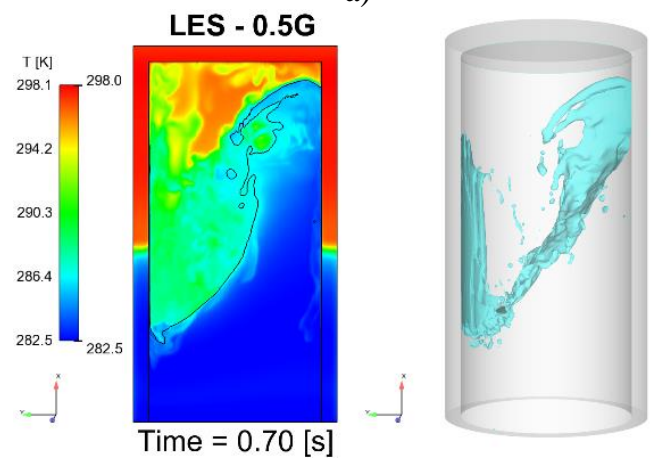

b)

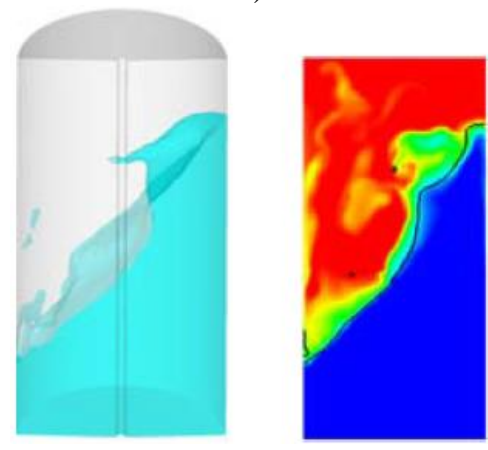

c)

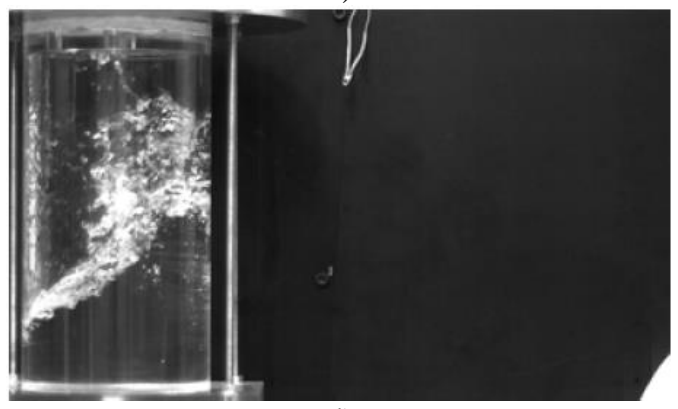

d)

Figure 34. Comparison of interface motion and temperature field at the center plane of the tank between current $k$ - $\omega S S T$ (a) and LES (b) models; results of simulation of Himeno et al. [2]

(c) and the experiment (d) after 0.7 seconds of sloshing

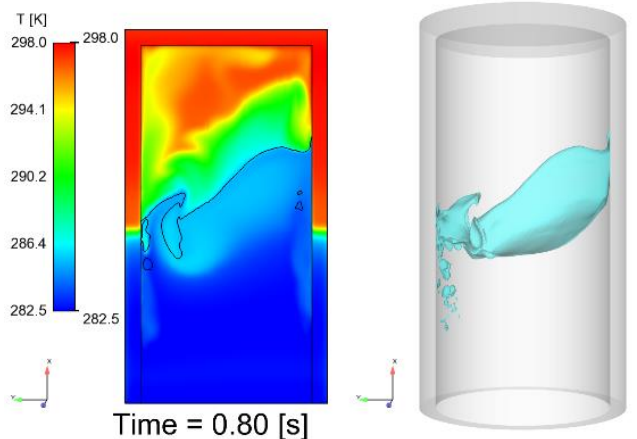

a)

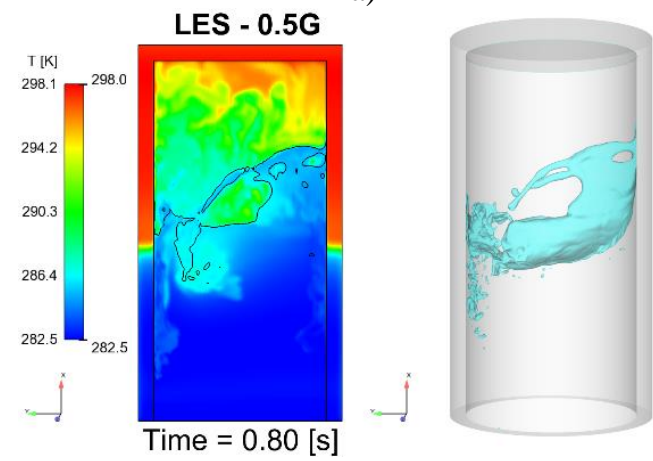

b)

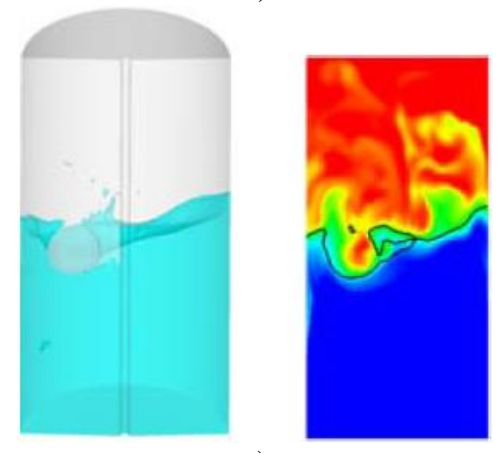

c)

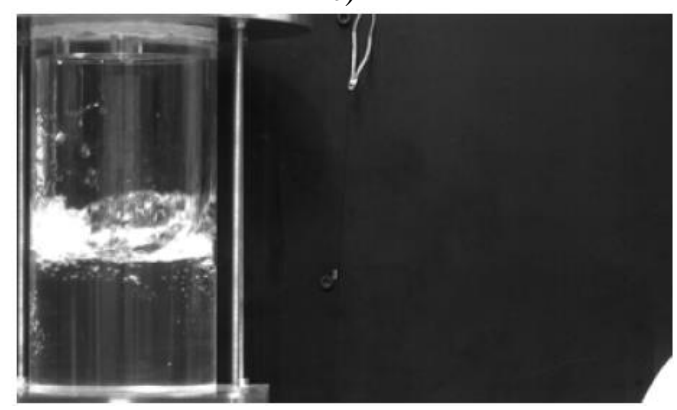

d)

Figure 35. Comparison of interface motion and temperature field at the center plane of the tank between current $k$ - $\omega S S T$ (a) and LES (b) models; results of simulation of Himeno et al. [2]

(c) and the experiment (d) after 0.8 seconds of sloshing 


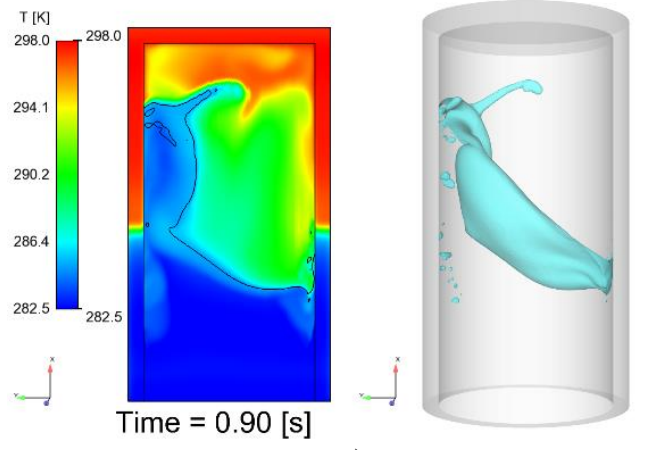

a)

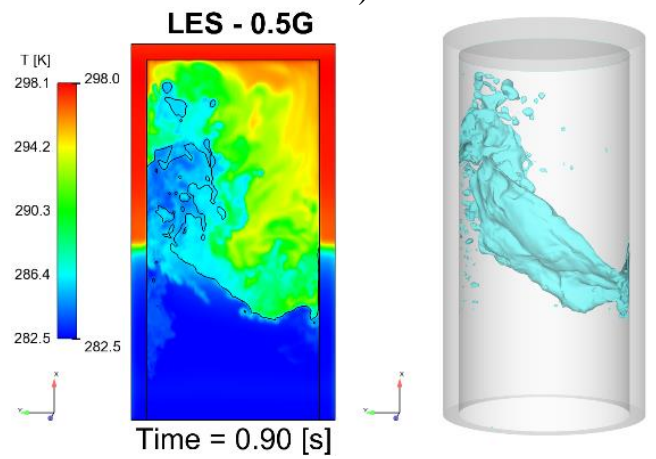

b)

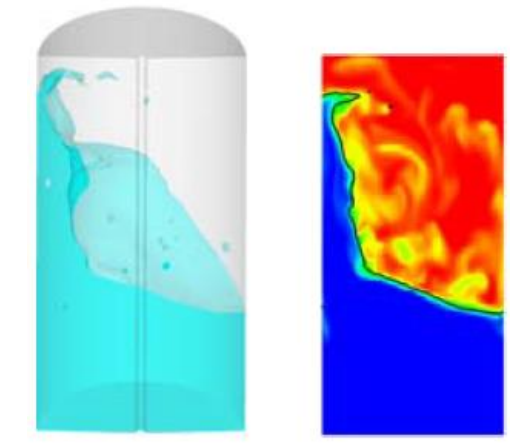

c)

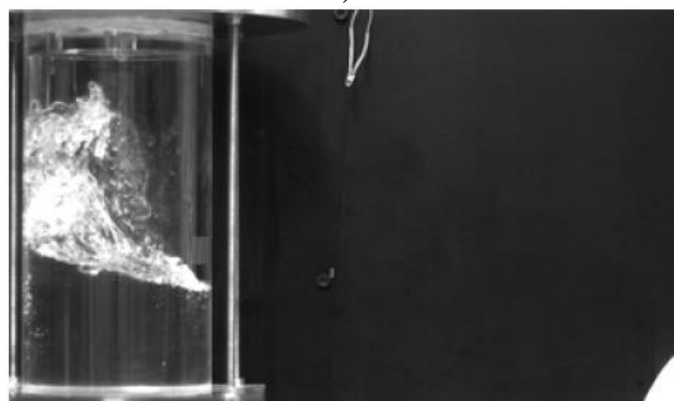

d)

Figure 36. Comparison of interface motion and temperature field at the center plane of the tank between current $k$ - $\omega S S T$ (a) and LES (b) models; results of simulation of Himeno et al. [2]

(c) and the experiment (d) after 0.9 seconds of sloshing

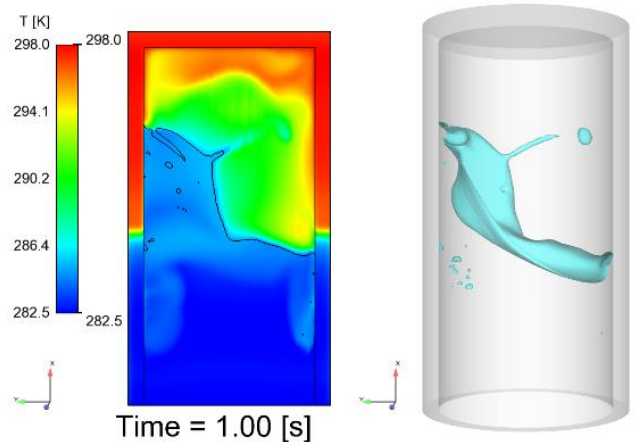

a)

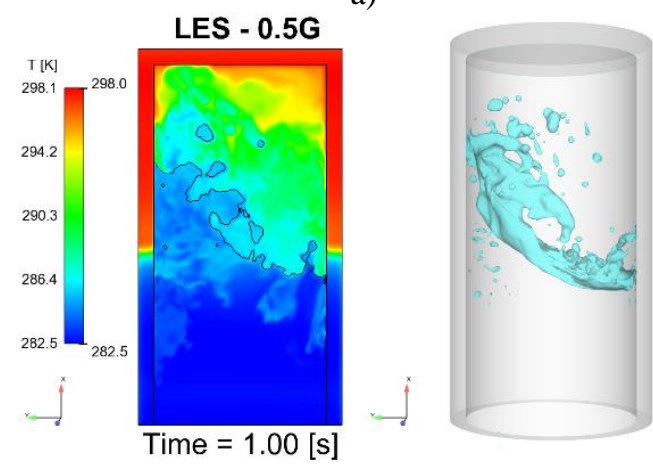

b)

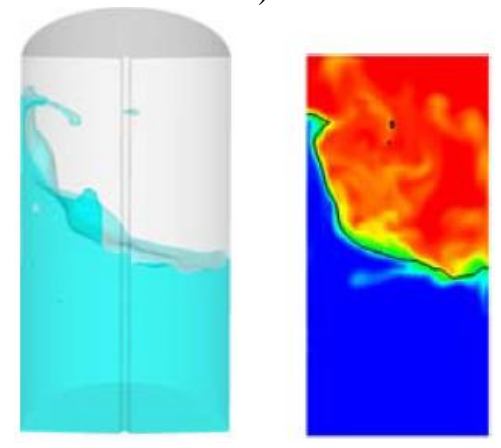

c)

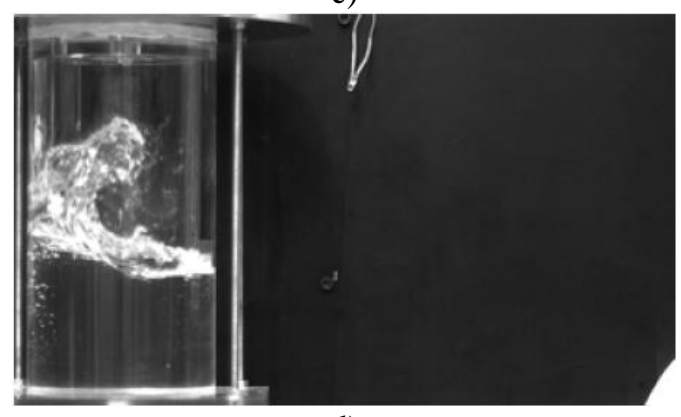

d)

Figure 37. Comparison of interface motion and temperature field at the center plane of the tank between current $k$ - $\omega S S T$ (a) and LES (b) models; results of simulation of Himeno et al. [2]

(c) and the experiment (d) after 1.0 seconds of sloshing 


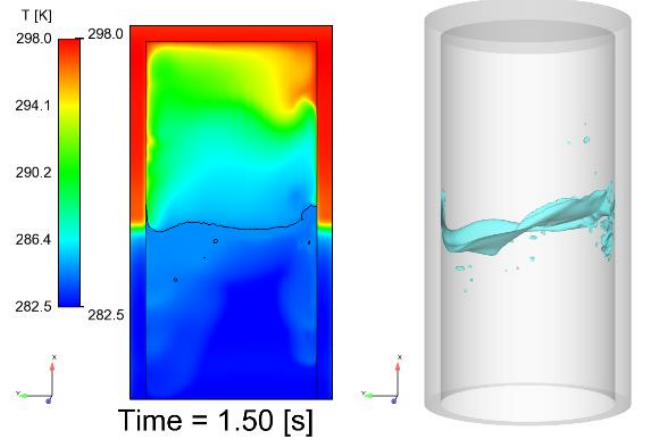

a)

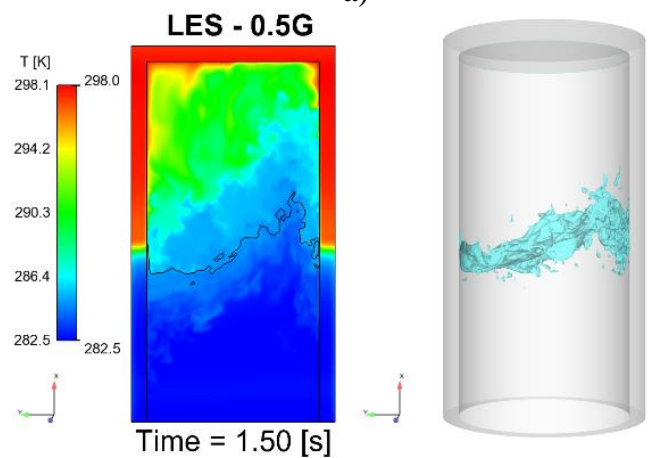

b)

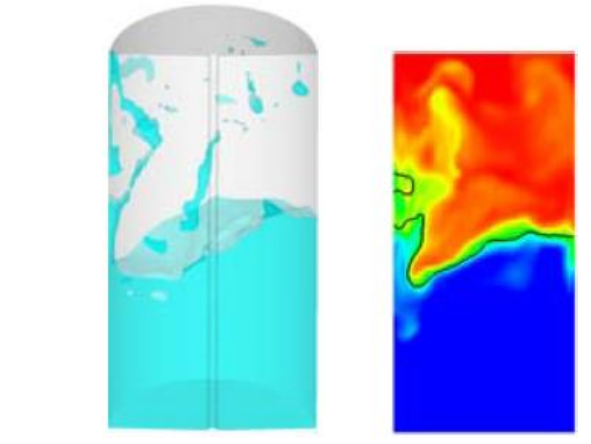

c)

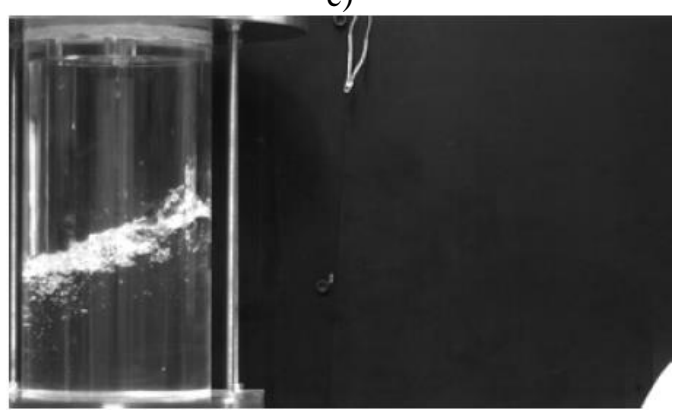

d)

Figure 38. Comparison of interface motion and temperature field at the center plane of the tank between current $k$ - $\omega S S T$ (a) and LES (b) models; results of simulation of Himeno et al. [2]

(c) and the experiment (d) after 1.5 seconds of sloshing

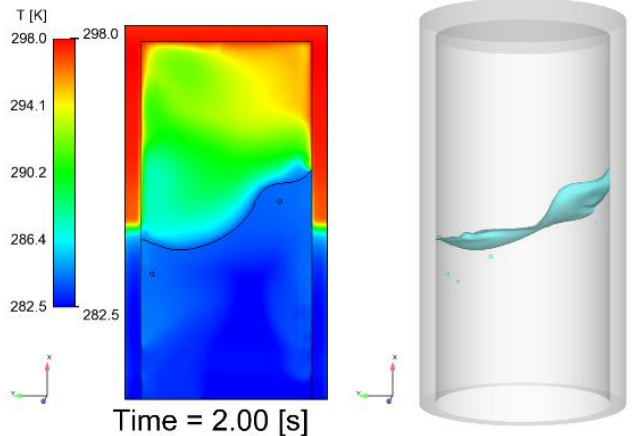

a)

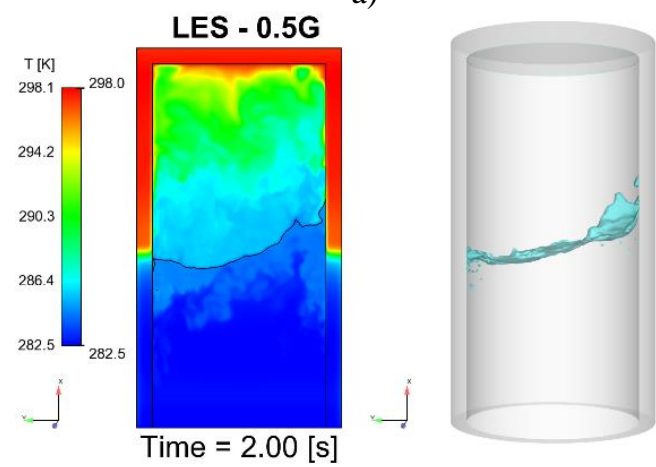

b)

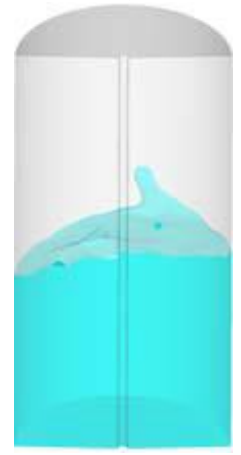

c)

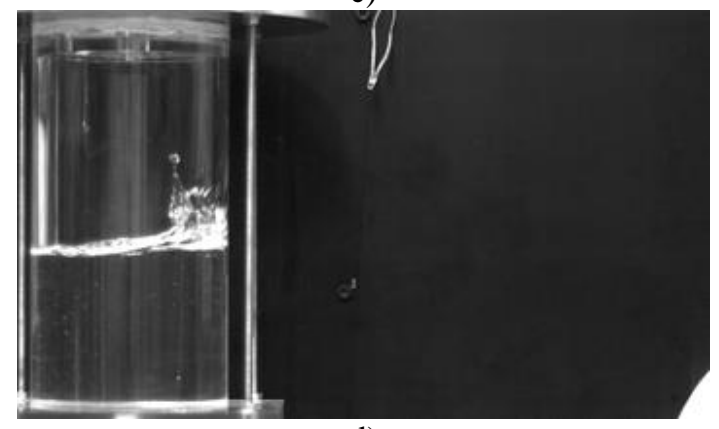

d)

Figure 39. Comparison of interface motion and temperature field at the center plane of the tank between current $k-\omega S S T$ (a) and LES (b) models; results of simulation of Himeno et al. [2]

(c) and the experiment (d) after 2.0 seconds of sloshing 


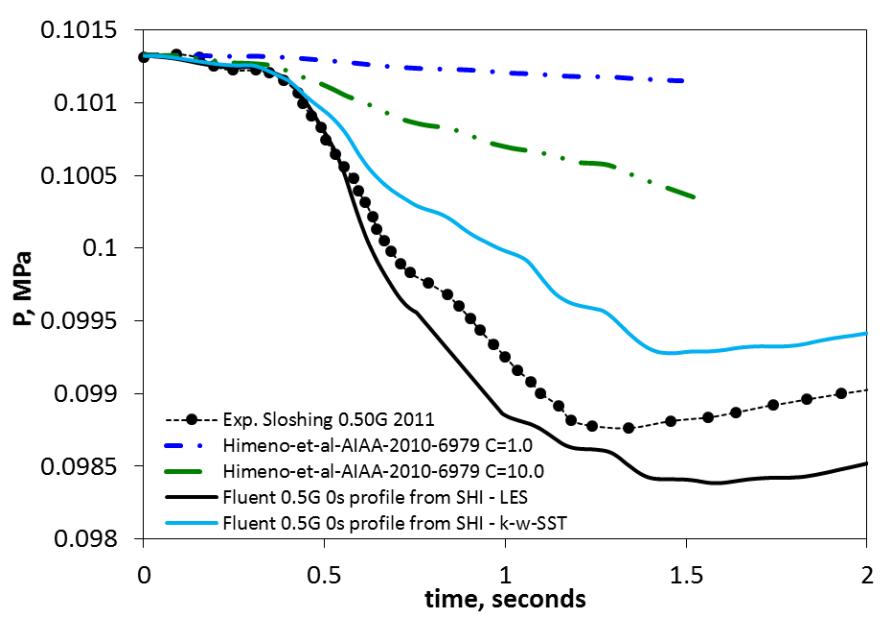

Figure 40. Pressure evolution in the tank during sloshing: Comparison between predictions of the current models and CFD results reported by Himeno et al. [2]

\section{ACKNOWLEDGMENTS}

This work was supported by the NASA Space Technology Mission Directorate's Technology Demonstration Missions Program under the Evolvable Cryogenics Project.

\section{REFERENCES}

[1] T. Himeno, D. Sugimori, K. Ishikawa, Y. Umemura, T. Uzawa, C. Inoue, T. Watanabe, S. Nonaka, Y. Naruo, Y. Inatani, K. Kinefuchi, R. Yamashiro, T. Morito, K. Okita "Heat Exchange and Pressure Drop Enhanced by Sloshing", Proceedings of the 47th AIAA/ASME/SAE/ASEE Joint Propulsion Conference and Exhibit, San Diego, CA, USA, 2011, AIAA-2011-5682.

[2] T. Himeno, D. Sugimori, T. Uzawa, K. T. Watanabe, S. Nonaka "Heat Exchange and Pressure Drop Enhanced by Violent Sloshing", Proceedings of the 46th AIAA/ASME/SAE/ASEE Joint Propulsion Conference and Exhibit, Nashville, TN, USA, 2010, AIAA-2010-6979

[3] Iglesias, A.S., Rojas, L.P. and Rodriguez, R.Z., "Simulation of anti-roll tanks and sloshing type problems with smoothed particle hydrodynamics", Ocean Eng., 31(8-9), 1169-1192, 2004.

[4] Nam, B.W. and Kim, Y., "Simulation of two-dimensional sloshing flows by SPH method", Proceedings of the International Offshore and Polar Engineering Conference, San Francisco, CA, USA, 2006.

[5] Lee, D.H., Kim, M.H., Kwon, S.H., Kim, J.W. and Lee, Y.B., "A parametric sensitivity study on LNG tank sloshing loads by numerical simulations", Ocean Eng., 34(1), 3-9, 2005.

[6] Wemmenhove, R., Luppes, R., Veldman, A.E.P. and Bunnik, T., "Numerical simulation of sloshing in LNG tanks with a compressible two-phase model", Proceedings of the 26th International Conference on Offshore Mechanics and Arctic Engineering, San Diego, CA, USA, 2007.

[7] Wemmenhove, R., Iwanowski, B., Lefranc, M., Veldman, A.E.P., Luppes, R. and Bunnik, T., "Simulation of Sloshing dynamics in a tank by an improved volume-of-fluid method", Proceedings of the 19th International Offshore and Polar Engineering Conference, Osaka, Japan, 2009.

[8] Chen, H.C. "Time-domain simulation of nonlinear wave impact loads on fixed offshore platform and decks", Int. J. Offshore Polar, 20(4), 275-283, 2010.

[9] Chen, H.C. and Yu, K. "Numerical simulation of wave run up and green water on offshore structures by a level-set RANS method," Proceedings of the 16th International Offshore and Polar Engineering Conference, San Francisco, CA, USA, 2006.

[10] Chen, Y.G., Price W.G. and Temarel, P. "Numerical simulation of liquid sloshing in LNG tanks using a compressible two-phase flow model", Proceedings of the 19th International Offshore and Polar Engineering Conference, Osaka, Japan, 2009.

[11] Abramson, H. N. "The dynamic behavior of liquids in moving containers" NASA SP 106, 1966.

[12] Lacapere, J., Vielle, B., and Legrand, B. "Experimental and Numerical Results of Sloshing with Cryogenic Fluids." Progress in Propulsion Physics, 1, pp. 267-278, 2009.

[13] J. Agui and J. Moder "Modeling of Non-isothermal Cryogenic Fluid Sloshing", 51st AIAA/ASME/SAE/ASEE Joint Propulsion Conference and Exhibit, Orlando, FL, 2015, AIAA-2015-4072.

[14] Hirt, C.W., and Nichols B.D., "Volume of fluid (VOF) method for the dynamics of free boundaries," Journal of Computational Physics, 39(1), 1981, pp. 201-225.

[15] Brackbill J.U., Kothe, D.B., Zemach, C., "A continuum method for modeling surface tension," J. Comp. Phys. 100, 1992, pp. 335-354.

[16] Menter, F. R., “Two-Equation Eddy-Viscosity Turbulence Models for Engineering Applications," AIAA Journal, 32(8), 1994, pp. 1598-1605.

[17] Wilcox, D.C., Turbulent Modeling for CFD, DCW Industries, Inc., La Canada, California, 1998.

[18] Bradshaw, P., Ferriss, D.H., and Atwell, N.P., "Calculation of Boundary-Layer Development Using the Turbulent Energy Equation,” Journal of Fluid Mechanics, 28(3), 1967, pp. 593-616.

[19] F. Nicoud and F. Ducros. "Subgrid-Scale Stress Modelling Based on the Square of the Velocity Gradient Tensor." Flow, Turbulence, and Combustion, 62(3):183-200, 1999.

[20] ANSYS Fluent Documentation. Release 17.0. 